\title{
On the morphological variability of Ichniotherium tracks and evolution of locomotion in the sistergroup of amniotes
}

\author{
Michael Buchwitz ${ }^{\text {Corresp., } 1}{ }^{\text {， Sebastian Voigt }}$ Corresp. $2^{\text {. }}$ \\ 1 Museum für Naturkunde Magdeburg, Magdeburg, Germany \\ 2 Urweltmuseum Geoskop, Kusel, Germany \\ Corresponding Authors: Michael Buchwitz, Sebastian Voigt \\ Email address: michael.buchwitz@museen.magdeburg.de, s.voigt@pfalzmuseum.bv-pfalz.de
}

Ichniotherium tracks with a relatively short pedal digit V (digit length ratio V/IV $<0.6$ ) form the majority of yet described Late Carboniferous to Early Permian diadectomorph tracks and can be related to a certain diadectid clade with corresponding phalangeal reduction that includes Diadectes and its close relatives. Here we document the variation of digit proportions and trackway parameters in 25 trackways (69 step cycles) from nine localities and seven further specimens with incomplete step cycles from the type locality of Ichniotherium cottae (Gottlob quarry) in order to find out whether this type of Ichniotherium tracks represents a homogeneous group or an assemblage of distinct morphotypes and includes variability indicative for evolutionary change in trackmaker locomotion. According to our results, the largest sample of tracks from three Lower Permian sites of the Thuringian Forest, commonly referred to Ichniotherium cottae, is not homogeneous but shows a clear distinction in pace length, pace angulation, apparent trunk length and toe proportions between tracks from Bromacker quarry and those from the stratigraphically older sites Birkheide and Gottlob quarry. Three Late Carboniferous trackways of Ichniotherium with relatively short pedal digit $V$ from Haine's Farm, Ohio, and Alveley near Birmingham, United Kingdom, that have been referred to the ichnotaxa "Baropus hainesi", "Megabaropus hainesi" and "Ichniotherium willsi", respectively, share a marked outward rotation of foot imprints with respect to walking direction. Apart from this feature they are in many aspects similar to the Birkheide and Gottlob records of Ichniotherium cottae. With the possible exception of the Maroon Formation (Early Permian, Colorado) sample, Early Permian Ichniotherium trackways with a relatively short pedal digit $V$ fall into the morphological spectrum of the three well defined 'Hainesi-Willsi', 'Birkheide-Gottlob' and 'Bromacker' morphotypes. With their more obtuse pace angulations and higher body-size-normalized pace and stride lengths the Bromacker type tracks imply higher walking speeds of their trackmakers compared to all other Ichniotherium tracks. More generally, a trend towards higher locomotion capability from the last common 
ancestor of all Ichniotherium producers to the last common ancestor of all "Ichniotherium with relatively short pedal digit V" and from the latter to the trackmakers of the mid-Early Permian Bromacker type can be deduced - with the reservation that overall sample size is relatively small, making this scenario a preliminary assessment. Whether the presumed advancements represent a more general pattern within diadectomorphs, remains open until the non-European Ichniotherium trackway record improves. Ichnotaxonomic implications are discussed. 
1 On the morphological variability of Ichniotherium tracks and evolution of

2 locomotion in the sistergroup of amniotes

3

4 Michael Buchwitz $^{1}$ and Sebastian Voigt ${ }^{2}$

5

6

$7 \quad{ }^{1}$ Museum für Naturkunde Magdeburg, Otto-von-Guericke-Straße 68-73, 39104

8 Magdeburg, Germany.

9 2Urweltmuseum Geoskop, Burgstraße 19, 66871 Thallichtenberg, Germany. 10

11 Corresponding author: Michael Buchwitz; phone: +49(0)176-51929542

12 E-mail addresses: michael.buchwitz@museen.magdeburg.de (M. Buchwitz)

13 s.voigt@pfalzmuseum.bv-pfalz.de (S. Voigt). 


\section{On the morphological variability of Ichniotherium tracks and evolution of} locomotion in the sistergroup of amniotes

\section{Abstract}

19

Ichniotherium tracks with a relatively short pedal digit $\mathrm{V}$ (digit length ratio $\mathrm{V} / \mathrm{IV}<0.6$ ) form the majority of described Late Carboniferous to Early Permian diadectomorph tracks and can be related to a certain diadectid clade with corresponding phalangeal reduction that includes Diadectes and its close relatives. Here we document the variation of digit proportions and trackway parameters in 25 trackways (69 step cycles) from nine localities and seven further specimens with incomplete step cycles from the type locality of Ichniotherium cottae (Gottlob quarry) in order to find out whether this type of Ichniotherium tracks represents a homogeneous group or an assemblage of distinct morphotypes and includes variability indicative for evolutionary change in trackmaker locomotion. According to our results, the largest sample of tracks from three Lower Permian sites of the Thuringian Forest, commonly referred to Ichniotherium cottae, is not homogeneous but shows a clear distinction in pace length, pace angulation, apparent trunk length and toe proportions between tracks from Bromacker quarry and those from the stratigraphically older sites Birkheide and Gottlob quarry. Three Late Carboniferous trackways of Ichniotherium with relatively short pedal digit $\mathrm{V}$ from Haine's Farm, Ohio, and Alveley near Birmingham, United Kingdom, that have been referred to the ichnotaxa "Baropus hainesi", "Megabaropus hainesi" and "Ichniotherium willsi", respectively, share a marked outward rotation of foot imprints with respect to walking direction. Apart from this feature they are in many aspects similar to the Birkheide and Gottlob records of Ichniotherium cottae. With the possible exception of the Maroon Formation (Early Permian, Colorado) sample, Early Permian Ichniotherium trackways with a relatively short pedal digit $\mathrm{V}$ fall into the morphological spectrum of the three well defined 'Hainesi-Willsi', 'BirkheideGottlob' and 'Bromacker' morphotypes. With their more obtuse pace angulations and higher body-size-normalized pace and stride lengths the Bromacker type tracks imply higher walking speeds of their trackmakers compared to all other Ichniotherium tracks. More generally, a trend towards higher locomotion capability from the last common ancestor of all Ichniotherium producers to the last common ancestor of all "Ichniotherium with relatively short pedal digit V" and from the latter to the trackmakers of the mid-Early Permian Bromacker type can be deduced - with the reservation that overall sample size is relatively small, making this scenario a preliminary assessment. Whether the presumed advancements represent a more general pattern within diadectomorphs, remains open until the non-European Ichniotherium trackway record improves. Ichnotaxonomic implications are discussed. 


\section{Introduction}

Ichniotherium Pohlig, 1892 is a common and widespread kind of Late Carboniferous and Early Permian tetrapod footprints referred to diadectomorph trackmakers (Haubold, 2000; Voigt \& Haubold, 2000; Voigt, 2005, 2012; Voigt, Small \& Sanders, 2005; Voigt, Berman \& Henrici, 2007; Voigt et al., 2011, 2012; Voigt \& Ganzelewski, 2010; Brink, Hawthorn \& Evans, 2012; Voigt \& Lucas, 2015, 2017a, b). Tracks of this type were discovered for the first time in Early Permian continental deposits of the Thuringian Forest, central Germany (Cotta, 1848). During the last 150 years, Ichniotherium tracks have been given at least 10 different ichnogeneric, 10 ichnospecific and 11 ichnosubspecific names (see Voigt, 2005, appendix 15). A rather recent careful revision of the central European Ichniotherium record (Voigt, 2005; Voigt, Berman \& Henrici, 2007; Voigt and Ganzelewski, 2010) argued for a single ichnogenus and three valid ichnospecies: Ichniotherium cottae (Pohlig, 1885), Ichniotherium sphaerodactylum (Pabst, 1895) and Ichniotherium praesidentis (Schmidt, 1956).

Ichniotherium cottae on the one hand and Ichniotherium sphaerodactylum and Ichniotherium praesidentis on the other are separated by pedal digit proportions considering that pedal digit $\mathrm{V}$ is about as long as pedal digit II in Ichniotherium cottae whereas it is usually as long as pedal digit III in the two remaining ichnospecies (Voigt and Ganzelewski, 2010). A quantitative expression of this distinction criterion is the pedal digit length ratio IV/V and a linear discriminant function based on these digit lengths $\left(F=1.2264 * p_{I V}-1.9728 * p_{V}-3.48281\right.$;

Fig. 1, Supplemental S1). Ichniotherium sphaerodactylum and Ichniotherium praesidentis, which differ considerably in the imprint morphology of the manus as well as in the trackway pattern, are very rare and have only been recorded from central Germany (Voigt, 2005; Voigt and Ganzelewski, 2010), Morocco (Voigt, Saber, Schneider, Hmich \& Hminna, 2011) and Canada (Brink, Hawthorn \& Evans, 2012).

Ichniotherium tracks with relatively short pedal digit $\mathrm{V}$ (length ratio $p_{\mathrm{V}} / \mathrm{p}_{\mathrm{IV}}<0.6$ ) are much more common with undoubted occurrences from the Czech Republic (Fritsch, 1887, 1895, 1912), Germany (Pabst, 1908; Haubold, 1971; Haubold \& Stapf, 1998; Voigt \& Haubold, 2000; Voigt, 2005, 2012), Great Britain (Haubold \& Sarjeant, 1973, 1974), Morocco (Lagnaoui, Voigt, Belahmira, Saber, Klein, Hminna \& Schneider, in press), Poland (Pabst, 1908; Voigt, Niedźwiedzki, Raczyński, Mastalerz \& Ptaszyński, 2012), and the United States of America (Carman, 1927; Baird, 1952; Voigt et al., 2005; Voigt \& Lucas, 2015, 2017b). During the last decade numerous additional finds and yet unpublished revision studies of previously recorded but misidentified specimens significantly extended the global record of Ichniotherium tracks with relatively short pedal digit $\mathrm{V}$. Among these records only some include a notable sample of actual trackways, i.e. imprint sequences comprising one or several step cycles - a necessary precondition for their consideration in this approach which follows the directive that taxonomy 
89 of vertebrate tracks shall not merely be based on imprint morphology but take into account 90 trackway features.

91 With some exceptions (e.g., Ruta and Coates, 2007), phylogenetic analyses of basal 92 amniotes and their non-amniote relatives recovered the diadectomorphs as a monophylum 93 that forms the sistergroup to amniotes and consists of Limnoscelis, Tseajaia as well as five or 94 more diadectid taxa that range from the Late Carboniferous through the late Early Permian 95 (e.g., Laurin \& Reisz 1999, 2007; Ruta, Coates \& Quicke, 2003; Reisz 2007, Kissel 2010; Fig. 2). If 96 the assignment of a fragmentary skull from China to diadectids by Liu \& Bever (2015) is confirmed, it would extend the range of this group by over 15 million years into the Late Permian. Based on the unique track-trackmaker co-occurrences of the Early Permian Bromacker site in central Germany (Voigt, Berman \& Henrici, 2007), Ichniotherium sphaerodacty/um with relatively long pedal digit V can be related to Orobates pabsti (Berman et al., 2004), whereas Ichniotherium cottae with relatively short pedal digit $\mathrm{V}$ is likely to be the track of Diadectes absitus (Berman, Sumida \& Martens, 1998), which has been referred to the new genus Silvadectes by Kissel (2010). A short pedal digit $V$ and phalangeal formula 2-3-4-5-3 has been documented for the North American Diadectes specimen CM 41700 (and was probably also present in Diadectes ("Silvadectes") absitus, see Voigt, Berman \& Henrici, 2007) whereas the relatively long pedal digit $\mathrm{V}$ and pedal phalangeal formula 2-3-4-5-4 occurs in both, the basal diadectomorph Limnoscelis (e.g., Kennedy, 2010: fig. 8) and the diadectid Orobates. Thus, we consider a clade of diadectids which share a pes with relatively short digit $\mathrm{V}$ and are more closely related to the North American species of Diadectes (sensu Kissel, 2010) than to Orobates as the potential producer group of all documented Ichniotherium tracks with relatively short pedal digit V. This type of Ichniotherium represents a well-defined subset of all Ichniotherium

112 tracks (including Ichniotherium cottae from the Thuringian forest) and spans 20 million years of 113 the geological record.

114 In order to find out whether Ichniotherium with relatively short pedal digit V, a) can be 115 subdivided into ichnotaxonomically relevant morphotypes based on imprint and trackway 116 measurement data and b) includes variability indicative for evolutionary change in trackmaker 117 locomotion, the following steps are undertaken in the present approach:

118 (1) Documentation of the variability of imprint and trackway measures in Ichniotherium 119 cottae tracks from three localities of the Thuringian Forest in central Germany, i.e. 120 Gottlob/Friedrichroda (Ichniotherium cottae type locality), Birkheide/Tambach-Dietharz and 121 Bromacker/Tambach-Dietharz as a reference sample for Ichniotherium with relatively short 122 pedal digit $\mathrm{V}$.

123 (2) Comparison of the Thuringian Forest record to Late Carboniferous and Permian 124 records from Europe and North America, and, if feasible, distinction of trackway morphotypes. 
125 Taking the varying sample sizes into account, numerical discrimination schemes shall be derived

126 for the largest samples and are then to be used for the classification of isolated trackways.

127 (3) Discussion of ichnotaxonomic consequences for Ichniotherium with relatively short 128 pedal digit $\mathrm{V}$.

129 (4) Inference of evolutionary change in trackway and imprint measures based on a 130 phylogenetic hypothesis of Ichniotherium trackmaker relationships and discussion of individual

131 track-trackmaker assignments.

132 (5) Inference of evolutionary change in diadectomorph locomotion based on 133 phylogenetic trends in functionally relevant trackway/imprint measures and discussion of 134 factors limiting interpretation at the present state of knowledge.

135

\section{Materials and Methods}

137

138

(1) Material

139

Based on the distinction criterion given above (pedal digit length ratio <0.6; $F>0$, see Supplemental S1) only trackways with at least one step cycle preserved are considered herein. Because of the sparse trackway record from the Ichniotherium cottae type locality Gottlob quarry (Thuringian Forest, central Germany) we have made an exception and included seven specimens with incomplete Ichniotherium step cycles (HF 57, HF 89, MNG 1381, MNG 1382, MNG 1385, MNG 1387, MNG 1781; Fig. 3) from this site. The present analysis includes the following 25 Ichniotherium specimens that include at least one complete step cycle (Table 1, Supplemental S2, Figs. 4-10): BU 2471, CMNH VP-3052, DMNS 50618, DMNS 50622, DMNS 55056, KGM-1, MB.ICV.3-F1, MB.ICV.3-F2, MC-1, MNG 1352, MNG 1386-F1, MNG 1819, MNG 2047, MNG 2049, MNG 2356-16-F1, MNG 2356-16-F2, MNG 10179, MSEO-I-36, NHMS AP-24419, NHMS P-418, OSU 16553, PMJ P-1321-F3, SSB-1, UGKU 130-F1, UGKU 130-F2. All materials have been studied, documented und measured by one of us (SV) between 1998 and 2015.

\section{(2) Institutional abbreviations}

153 BU, Lapworth Museum of Geology, University of Birmingham, Great Britain; CMNH, Cincinnati 154 Museum of Natural History, Cincinnati, USA; DMNS, Denver Museum of Nature and Science, Denver, USA; HF, Institut für Geologische Wissenschaften und Geiseltalmuseum, Martin-Luther-

156 Universität Halle-Wittenberg, Germany; KGM, Kletno Geological Museum, Poland; MB, 157 Museum für Naturkunde, Berlin, Germany; MC, Marietta College, Ohio, USA; MNG, Museum 158 der Natur Gotha, Germany; MSEO, Museum Schloss Ehrenstein, Ohrdruf, Germany; NHMS, 159 Naturhistorisches Museum Schloss Bertholdsburg, Schleusingen, Germany; OSU, Orton 160 Geological Museum, Ohio State University, Columbus, USA; PMJ, Phyletisches Museum Jena, 
161 Germany; SSB, Sammlung Stober, private collection, Berlin, Germany; UGKU, POLLICHIA

162 Geoscience Collections, Urweltmuseum Geoskop, Burg Lichtenberg, Thallichtenberg, Germany.

163

164 (3) Use of imprint and trackway parameters

165 Considering their robustness as imprint measures, we focus here on digit proportions as the 166 sole criterion for imprint shape. Length of pedal digit IV, usually the longest toe of an imprint 167 pair, is used as a proxy for body size and for normalization of other toe lengths: $p_{I}(n)=p_{I} / p_{I V}$, $168 p_{\mathrm{II}}(n)=p_{\mathrm{II}} / p_{\mathrm{IV}}, \ldots, m_{\mathrm{V}}(n)=m_{\mathrm{V}} / p_{\mathrm{IV}}$. If only manual imprint proportions are considered we also use 169 the ratios $m_{l} / m_{I V}, m_{I /} / m_{I V}, m_{I I} / m_{I V}$ and $m_{V} / m_{I V}$ (Supplemental S3, Fig. $11 \mathrm{~A}$ ). Concerning the use 170 of pedal and manual digit length IV as normalization values we are following the convention of 171 earlier studies (e.g. Voigt, Berman \& Henrici 2007; Voigt \& Ganzelewski 2010; contra Romano \&

172 Citton 2005). Both measures are highly correlated with the average of all other toe lengths 173 (correlation coefficients between 0.968 and 0.993 ) pedal digit length IV also shows high 174 correlation with pes length (correlation coefficients between 0.930 and 0.964 ; see 175 Supplemental S4) and thus can be considered as a reasonable body size proxy. Despite the 176 uncertainties that can occur in free digit length measurements (Fig. 11B-D), pedal and manual 177 digit length IV are usually better recognizable than the overall imprint length which is often 178 obscured by an indistinctly preserved posterior margin.

179 In order to compare trackway patterns in detail we consider each step cycle of a 180 trackway as an individual dataset whose important attributes include the manual and pedal 181 pace angulations $\left(\alpha_{p}\right.$ and $\left.\alpha_{m}\right)$, the deviation of manual and pedal imprint orientations from 182 walking direction $\left(\beta_{p}\right.$ and $\beta_{m}$, positive value $=$ inward rotation $=$ dextral rotation of left 183 hand/foot = sinistral rotation of the right hand/foot $)$, normalized pace length $\left(P_{p}(n)=\right.$ average of 184 two pedal pace lengths / length of pedal digit IV), normalized apparent trunk length $(C(n)=$ 185 apparent trunk length / $\mathrm{p}_{\mathrm{IV}}$; see scheme in Fig. 11A; Supplemental S4). Although they are 186 redundant measures that can be calculated from normalized pace length and pace angulation 187 in case of a regular trackway pattern, we also take the normalized stride length and trackway 188 width $\left(\mathrm{S}_{\mathrm{p}}(\mathrm{n})=\right.$ pedal stride length $/ \mathrm{p}_{\mathrm{IV}} ; \mathrm{B}_{\mathrm{p}}(\mathrm{n})=$ pedal trackway gauge width / $\left.\mathrm{p}_{\mathrm{IV}}\right)$ into account 189 since they represent useful indicators for functional variation in track producers. For the 190 normalization of trackway measures $P_{p}(n), C(n), S_{p}(n)$ and $B_{p}(n)$ the trackway average of pedal 191 digit length IV is used.

192

\section{3 (4) Quantitative comparison of trackway records}

194 Toe proportions and trackway parameters are analyzed as separate datasets. All localities are 195 represented by sets of imprint pairs and step cycles, whose toe proportions and trackway 196 parameters are compared - mainly through methods of multivariate statistics for which the 197 statistical software package PAST is used (Hammer et al., 2001). We use bivariate plots and 
198 Principal Component Analysis (PCA) to explore the datasets for noteworthy differences 199 between sampled localities and Multivariate Analysis of Variance (MANOVA) to test whether 200 the supposed differences between localities are statistically significant. It should be noted that the PCA results depicted in this manuscript are based on (a) covariance matrices of length ratios (normalized length measurements) or (b) correlation matrices of length ratios in combination with angle measurements. The representation of morphospace in our PC plots differs from that of PC plots based on landmark analysis that are used in geometric morphometrics. In addition to toe-ratio-based analyses we have also carried out PCAs based on logarithmized toe ratios which might reveal body-size related biasing in the distribution and overlap of groups (Supplemental Fig 2). If the separability between groups appears to be good enough we employ Linear Discriminant Analysis (LDA) - preferably based on a small set of parameters - to gain a linear discriminant function for classification of further individual tracks and smaller track records, e.g. the trackways from Tłumaczow/Poland and Marietta/Ohio (according to the previously found morphotypes).

Usually not all toes of an imprint pair are preserved well enough to be measured, often the lateral digits (pedal and manual digit V) are missing or their connection with the sole imprint is vague. Thus, for reasons of sample size, hand proportions $\left(m_{1}(n)\right.$ to $\left.m_{V}(n)\right)$ and toe proportions $\left(p_{I}(n)\right.$ to $\left.p_{V}(n)\right)$ are compared separately and only the proportions of the more often preserved manual and pedal digits are combined in multivariate analyses.

217

218

\section{Results}

219

220

221

\section{(1) Variation within the sample of Ichniotherium cottae from the Thuringian Forest}

Two separate principal component analyses that include (a) all pedal toe proportions (Fig. 12A) and (b) all manual toe proportions (Fig. 12B) show markedly deviant distributions for the Bromacker and Gottlob samples and for the Bromacker and Birkheide samples, respectively, within the first two principal components (plane of greatest variance); the distribution for the third locality lies in between (similar results for logarithmized toe ratios, see Supplemental Fig relatively short marginal digits $p_{1}, p_{v}$ and $m_{1}$ and relatively large manual imprints (higher ratio of manual digit IV to pedal digit IV) than those from Birkheide and Gottlob. This pattern is also visible in the bivariate plots $p_{I I}(n)$ vs. $p_{I}(n), p_{v}(n)$ vs. $p_{I}(n), m_{\|} / m_{I V}$ vs. $m_{1} / m_{I V}$ and $m_{I V}(n)$ vs. $m_{I}(n)$ (Fig. 12C-D). There is also some difference between Birkheide and Gottlob, but usually the degree of overlap is as high as or higher than that between one of them and the Bromacker sample. According to Multivariate Analyses of Variance (MANOVA) the deviation in pedal digit proportions is highly significant $(p<0.001)$ with a highly significant difference in case of the 
235 Birkheide samples (Table 3). The analysis of manual digit proportions yields a significant 236 difference only between the Bromacker and Birkheide samples; for the combination of $p_{I}(n)$, $237 p_{I I}(n), m_{I}(n)$ and $m_{I V}(n)$ test results also indicate a distinction between Bromacker and both of 238 the other sites. In neither pair-wise comparison the Birkheide tracks differ significantly from 239 those of Gottlob.

Only one true trackway from Gottlob, consisting of two step cycles, was available for this study. It is considerably closer to the Birkheide sample than to the Bromacker sample in most trackway measures $\left(\alpha_{p}, \alpha_{m}, P_{p}(n), C_{p}(n)\right.$ and $\left.S_{p}(n)\right)$ whereas the differences in average imprint orientations and trackway width $\left(B_{p}(n)\right)$ are small (Table 2, Fig. 13). Comparing the trackway measures for the Birkheide and Bromacker samples, a considerable deviation in manual and pedal pace angulation $\left(\alpha_{p}, \alpha_{m}\right)$, pedal pace length $\left(P_{p}(n)\right)$, and apparent trunk length $(C(n))$ results in well separated distributions in the plane of greatest variance (PC $1+P C 2=65.2 \%$ of variance, Fig.13A; use of logarithmized length ratios $P_{p}(n), C_{p}(n)$ leads only to minor changes in the distribution of groups, see Supplemental Fig 2) and significance tests based on all variables or subsets of four or three meaningful variables (Table 4) suggest that this difference between Birkheide and Bromacker is not due to random variation. If the one trackway from Gottlob is added to the data subset from Birkheide, the p-values of the employed tests are at least as low as for the Birkheide versus Bromacker test cases without inclusion of the Gottlob sample (Table 4 , last column). Following the lack of separability between the stratigraphically close Gottlob and Birkheide samples, both are considered as a joint sample in the following comparisons.

(2) Relation of Late Carboniferous and further Early Permian records to the Thuringian sample Given their relatively high marginal digit lengths $\left(m_{l}(n), p_{l}(n), p_{V}(n)\right)$, the toe proportions of the Late Carboniferous specimens from Alveley/England and Haine's Farm/Ohio are usually overlapping considerably with each other and with the distributions of the Birkheide-Gottlob sample but are distinct from that of the Bromacker sample (Fig. 14A-B). Relative length of the manual digit IV is high for the Alveley trackway (but with a considerable along-track variation between 40 and $54 \mathrm{~mm}$ ) and causes a certain deviation between Alveley and both, the Haine's Farm and Birkheide-Gottlob samples in the ratio of manual to pedal digit IV ( $m_{I V}(n)$; Fig. 14B). Imprint pairs of the Maroon Formation display toe proportions intermediate between the Bromacker sample and the other samples and the best separation from all other samples occurs in the normalized lengths of manual digits I and IV, which are both low in the Maroon Formation record (Fig. 14B). In accordance with the patterns visible in plots of two variables $\left(p_{I}(n)\right.$ vs. $p_{v}(n) ; m_{I}(n)$ vs. $\left.m_{I V}(n)\right)$, MANOVA results (Tables $\left.5-6\right)$ show that the three samples from Birkheide-Gottlob, Haine's Farm and Alveley cannot be distinguished from each other based on toe proportions. The Bromacker imprint pairs differ significantly from those of the other localities with the exception of the Maroon Formation record. If only three groups (Bromacker, 
272 Maroon and the rest) and a reduced set of variables $\left(p_{I}(n), p_{V}(n), m_{I}(n), m_{I V}(n)\right)$ are considered,

273 a moderately exact distinction scheme can be derived (Table 7, see functions $F(4)$ and $F(5)$ ).

274 A notably better distinction between the different samples can be reached based on six 275 principal trackway measures $\left(\beta_{p}, \beta_{m}, C(n), P_{p}(n), \alpha_{m}, \alpha_{p}\right)$, which is also visible in a PCA biplot 276 depicting PC 1 and 2 (69.4\% of total variance) in which distributions for most localities are only 277 lowly to moderately overlapping (Fig. 14C; a similar result is reached with logarithmized length 278 ratios $C(n), P_{p}(n)$, see Supplemental Fig 2). The Late Carboniferous specimens from Haine's Farm 279 and Alveley differ from other records in their more outward to parallel imprint orientations (Fig. 280 14D) and display distributions whose centers are often close to each other. The Bromacker sample is marked by comparatively high pace angulations, normalized pace lengths, normalized

282

283

284

285

286

287

288

289

290

291

292

293

294

295

296

297

298

299

300

301

302

303

304

305

306

307 stride lengths and normalized apparent trunk lengths (Table 2, Fig. 14E-F). The more inward orientation of manual and pedal imprints is similar to those of the Birkheide-Gottlob sample and unlike the Late Carboniferous records with the Maroon Formation sample lying in between (Fig. 14D). Because of two step cycles with very low normalized pedal pace length, the distribution of the Maroon Formation sample differs somewhat from the Birkheide-Gottlob and Late Carboniferous samples (Fig. 14E-F). According to MANOVA results based on five distinct samples (Bromacker, Birkheide-Gottlob, Haine's Farm, Alveley, Maroon) and six variables ( $\beta_{p}$, $\beta_{m}, C(n), P_{p}(n), \alpha_{m}, \alpha_{p}$ ) only the Bromacker sample differs significantly from the other four (first column in Table 6). When the Late Carboniferous records (Haine's Farm and Alveley) are put in a single group, most of the pair-wise test results become significant and only the distinction of the Maroon sample as a group of its own is not well supported (third column in table 6). Since only three trackway measures $\left(\beta_{p}, P_{p}(n), \alpha_{p}\right)$ yield most of the variation that is useful for the distinction of the four considered groups (Bromacker, Birkheide-Gottlob, Haine's-Farm-Alveley, Maroon) our trackway-pattern-based discrimination scheme is based on this reduced set of variables (columns two and four in Table 6; functions $F(1)-F(3)$ in Table 7, see Fig. 15-16).

According to linear discriminant functions based on toe proportions, imprint measures and samples from six localities (Table 7), the two individual trackways from the Słupiec Formation of Tłumaczow/Poland and from the Washington Formation of Marietta/Ohio fall into the spectrum of the Birkheide-Gottlob and Maroon samples (Table 8).

\section{Discussion}

\section{(1) Homogeneity of the Thuringian Forest sample of Ichniotherium cottae}

Based on the present dataset and results at hand we have no sufficient basis for a distinction between the Gottlob and Birkheide samples. The four trackways from Birkheide were made by smaller individuals than those imprints and short series from Gottlob but for the toe 
308 proportions the distributions for the two samples either overlap or are close to each other 309 (Tables 2-3; Fig. 12).

310 In the course of this study we found a surprising difference between the Bromacker 311 sample and older trackways from the Birkheide and Gottlob localities when all measures at 312 hand were compared. The Bromacker trackways are marked by high pace angulations, pace 313 lengths, stride lengths, and apparent trunk lengths and, apart from that, some of the marginal 314 toes $\left(m_{1}, p_{1}, p_{v}\right)$ were conspicuously shorter than in the older Thuringian Forest tracks (Figs. 12-

315 13, Tables 3-4). Moreover, in the Bromacker step cycles low pedal pace angulation appears to 316 be compensated by high normalized pace length and vice versa ( $r=-0.419$, see Fig. 13F) - at the 317 benefit of normalized stride length that does not fall below a certain value (6.25). Taken 318 together, these differences can arguably not be attributed to substrate differences or allometry 319 in a functionally and taxonomically identical trackmaker (given the similarly small imprint sizes 320 in both, Birkheide and Bromacker tracks) but actually reflect functionally distinct trackmakers. 321 One step cycle of a Bromacker trackway, SSB-1, with relatively short pace length causes much 322 of the overlap with the Birkheide and Gottlob samples (Figs. 13D-E, dashed area in Fig. 15A). 323 However, measures defining the trackway pattern suggest that this individual step cycle might 324 represent a part of a curved path and accordingly differs from the rest of the Bromacker sample 325 (see Fig. 4C,I).

\section{(2) Non-Thuringian record and distinction of trackway morphotypes}

328 According to toe proportions and most trackway measures the three trackways from the Late 329 Carboniferous of Alveley/Great Britain and Haine's Farm/Ohio fall within the range of the 330 Thuringian Forest sample - with one notable exception: Their pedal imprints share a distinctive 331 outward rotation (with respect to the direction of movement), a feature also noted in earlier 332 discussions of the Alveley specimen ("Ichniotherium willsi", see Voigt \& Ganzelewski 2010), and 333 the manual imprints often display a more parallel-to-midline orientation ( $<18^{\circ}$ inward rotation) 334 than those of the Thuringian Forest specimens ( $\beta_{p}$ and $\beta_{m}$ angles; see Fig. 14D, Fig. 15A). 335 Whereas length ratios and pace angulations might be more substrate-dependant, we consider 336 imprint orientation as one of the trackway pattern characteristics that is likely to be 337 anatomically controlled and indicative of a functionally distinct trackmaker. The separability of 338 the combined Alveley and Haine's Farm sample from the Bromacker and Birkheide-Gottlob 339 samples is supported by trackway-parameter-based multivariate analyses of variance (columns 3403 and 4 in Table 6).

341 Apart from very low normalized pace length values in two step cycles (of specimen 342 DMNS 55056, Figs. 8C,J, 14F, 15) and subtle differences in the toe proportions of the manual 343 imprints (relatively short manual digit IV, see Fig. 12B), the sample of three trackways from the 344 Maroon Formation falls into the ranges of the previously distinguished groups (Birkheide- 
345 Gottlob, Bromacker, Alveley + Haine's Farm). Their trackway measures are mostly overlapping 346 with the Birkheide-Gottlob sample but they show more parallel imprint orientations that 347 correspond to those seen in some step cycles of the Bromacker sample (Fig. 14D). Even though 348 some MANOVA results support a distinction of the Maroon Formation tracks at higher 349 significance levels $(0.05,0.01$; see Table 6$)$ it would fail at lower significance levels $(0.001$, 350 0.0001) and we find it likely that the deviations in length proportions of one Maroon trackway 351 are not anatomically controlled. Furthermore, our step-cycle-based analyses have the caveat 352 that step cycles from the same trackway can hardly be regarded as independent observations, a 353 requirement of the applied statistic tests which is not fully met in our approach (therefore 354 application of lower significance levels). In sum we regard only three morphotypes of 355 Ichniotherium with relatively short pedal digit $\mathrm{V}$ as sufficiently supported by the present 356 dataset: the 'Birkheide-Gottlob type' with is based on trackways and short series from the 357 Gottlob and Birkheide localities, the 'Bromacker type' which based on trackways from the 358 Bromacker locality and the 'Hainesi-Willsi type' which is based on trackways from the Alveley 359 and Haine's Farm localities. Pending further observations, the Maroon sample can be tentatively referred to the morphologically similar Birkheide-Gottlob type.

According to a set of linear discriminant functions derived from more specimen-rich samples, the trackways from Tłumaczow and Marietta are grouping with the Birkheide-Gottlob and Maroon samples (Tables 7 and 8). Thus, we tentatively refer them to the Birkheide-Gottlob type here as well.

\section{(3) Ichnotaxonomic consequences}

367

Voigt (2005) and Voigt, Berman \& Henrici (2007) distinguished two ichnospecies for Ichniotherium based on the co-occurrence of two diadectids and two corresponding morphologically distinct types of reptiliomorph footprints at the Bromacker locality. By including Schmidtopus praesidentis (Schmidt, 1956), an over 310-million-year old trackway of a large diadectomorph or possibly a more basal member of the amniote stem group, Voigt \& Ganzelewski (2010) expanded the morphological and temporal range of Ichniotherium considerably. Notwithstanding the problematic status of Ichniotherium praesidentis (that shall be discussed elsewhere), we keep the taxonomic scheme of an ichnogenus Ichniotherium with several species that shall at least include Ichniotherium sphaerodactylum with relatively long pedal digit $\mathrm{V}$ and all tracks considered here with relatively short pedal digit $\mathrm{V}$. The first available binomial name for Ichniotherium tracks with relatively short pedal digit $\mathrm{V}$ is Ichniotherium cottae (Pohlig, 1885) which is redefined here as all "Ichniotherium with relatively short pedal digit $\mathrm{V}$ (i.e. pedal digit ratio $\mathrm{V} / \mathrm{IV}<0.6$ )". Based on distinct trackway patterns and the somewhat weaker signal of variation in toe proportions we propose three morphotypes of Ichniotherium cottae (Fig. 15B): 
Birkheide-Gottlob type. Referred specimens: HF 57, HF 89, MNG 1381, MNG 1382, MNG 1385, MNG 1387, MNG 1386-F1, MNG 1781 from the Ichniotherium cottae type locality Gottlob 385 Quarry/Friedrichroda and MNG 2047, MNG 2049, NHMS AP-244-19, NHMS P-418 from

386

387

388

389

390

391

392

393

394

395

396

397

398

399

400

401

402

403

404

405

406

407

408

409

410

411

412

413

414

415

416

417 Birkheide Quarry/Tambach-Dietharz.

Diagnosis: Ichniotherium with ratio $\mathrm{p}_{\mathrm{V}} / \mathrm{p}_{\mathrm{IV}}<0.6$, parallel to inward rotation of the pedal imprints $\left(1\right.$ to $\left.25^{\circ}\right)$ and manual imprints $\left(8\right.$ to $40^{\circ}$ ), pace angulations: $80-102^{\circ}$ (manual), 85 $108^{\circ}$ (pedal), pedal pace length/$/ p_{\mathrm{IV}}: 4.2-5.0$, apparent trunk length $/ \mathrm{p}_{\mathrm{IV}}: 4.1-5.5$, pedal stride length/p $p_{\mathrm{IV}}: 4.7-7.0$, gauge width (pedal) $/ \mathrm{p}_{\mathrm{IV}}: 2.7-3.6$. Toe ratios based on imprints with at least four digit lengths preserved: $p_{\mathrm{I}} / \mathrm{p}_{\mathrm{IV}}: 0.36-0.60, \mathrm{p}_{\mathrm{V}} / \mathrm{p}_{\mathrm{IV}}: 0.46-0.59, \mathrm{~m}_{\mathrm{I}} / \mathrm{p}_{\mathrm{IV}}: 0.31-0.47, \mathrm{~m}_{\mathrm{IV}} / \mathrm{p}_{\mathrm{IV}}$ : 0.70-0.88.

Differential diagnosis: Negative values for $F(1)=0.226 * \alpha_{p}+7.786 * P_{p}(n)-60.405$, positive values for $F(2)=0.30594 * \beta_{p}-5.4972 * P_{p}(n)+27.8749$; positive values for $F(5)=$ $36.926 * \mathrm{pl}(\mathrm{n})+22.899 * \mathrm{pV}(\mathrm{n})-26.3278$ (see Table 7, Fig. 16). Linear discriminant functions based on toe proportions allow no separation from the Hainesi-Willsi type.

Bromacker type. Referred specimens: MB.ICV.3-F1, MB.ICV.3-F2, MNG 1352, MNG 1819, MNG 2356-16-F1, MNG 2356-16-F2, MNG 10179, MSEO-I-36, PMJ P-1321-F3, SSB-1, UGKU 130-F1, UGKU 130-F2.

Diagnosis: Ichniotherium with ratio $\mathrm{p}_{\mathrm{v}} / \mathrm{p}_{\mathrm{IV}}<0.6$, usually parallel to inward rotation of the pedal imprints $\left(-15\right.$ to $25^{\circ}$ ) and manual imprints ( 1 to $\left.39^{\circ}\right)$, pace angulations: $82-136^{\circ}$ (manual), $76-129^{\circ}$ (pedal), pedal pace length/p $\mathrm{p}_{\mathrm{IV}}: 4.2-5.8$, apparent trunk length/ $\mathrm{p}_{\mathrm{IV}}: 4.6-6.2$, pedal stride length/$/ p_{\mathrm{IV}}: 6.2$ - 9.8, gauge width (pedal)/p $\mathrm{p}_{\mathrm{IV}}: 2.2-4.4$. Toe ratios based on imprints with at least four digit lengths preserved: $\mathrm{p}_{\mathrm{l}} / \mathrm{p}_{\mathrm{IV}}: 0.27-0.48, \mathrm{p}_{\mathrm{v}} / \mathrm{p}_{\mathrm{IV}}: 0.39-0.55, \mathrm{~m}_{\mathrm{l}} / \mathrm{p}_{\mathrm{IV}}: 0.25-0.36$, $\mathrm{m}_{\mathrm{IV}} / \mathrm{p}_{\mathrm{IV}}: 0.79-1.14$.

Differential diagnosis: Positive values for $F(1)=0.226 * \alpha_{p}+7.786 * P_{p}(n)-60.405$; negative values for $F(5)=36.926 * \mathrm{pl}(\mathrm{n})+22.899 * \mathrm{pV}(\mathrm{n})-26.3278$.

Hainesi-Willsi type. Referred specimens: OSU 16553, CMNH VP-3052 from Haine's Farm/Ohio and BU 2471 from Alveley/Great Britain.

Diagnosis: Ichniotherium with ratio $\mathrm{pV} / \mathrm{plV}<0.6$ (trackway average), usually outward rotation of pedal imprints $\left(-37\right.$ to $\left.-6^{\circ}\right)$ and parallel orientation of manual imprints $\left(-9\right.$ to $\left.27^{\circ}\right)$, pace angulations: $82-108^{\circ}$ (manual), $83-103^{\circ}$ (pedal), ), pedal pace length/p $\mathrm{p}_{\mathrm{Iv}}$ : $4.4-5.0$, apparent trunk length/p $\mathrm{p}_{\mathrm{IV}}: 4.0-6.0$, pedal stride length/$/ \mathrm{p}_{\mathrm{IV}}: 5.7-7.4$, gauge width (pedal)/ $/ \mathrm{p}_{\mathrm{IV}}$ : 2.7 - 3.8. Toe ratios based on imprints with at least four digit lengths preserved: $\mathrm{p}_{\mathrm{l}} / \mathrm{p}_{\mathrm{IV}}: 0.38$ $0.58, \mathrm{p}_{\mathrm{v}} / \mathrm{p}_{\mathrm{Iv}}: 0.52-0.66, \mathrm{~m}_{\mathrm{l}} / \mathrm{p}_{\mathrm{IV}}: 0.32-0.46, \mathrm{~m}_{\mathrm{IV}} / \mathrm{p}_{\mathrm{IV}}: 0.74-1$. 
Differential diagnosis: Negative values for $F(1)=0.226 * \alpha_{p}+7.786 * P_{p}(n)-60.405$, negative

419 values for $F(2)=0.30594 * \beta_{p}-5.4972 * P_{p}(n)+27.8749$; positive values for $F(5)=$ $42036.926 * \mathrm{pl}(\mathrm{n})+22.899 * \mathrm{pV}(\mathrm{n})-26.3278$. Linear discriminant functions based on toe proportions 421 allow no separation from the Birkheide-Gottlob type.

422

423 Not considered as a type of its own here, the sample of three trackways from the Maroon 424 Formation (DMNS 50618, DMNS 50622, DMNS 55056) can be distinguished from the three 425 morphotypes by a combination of low normalized pace lengths and pedal imprint orientations 426 that are rather parallel to the trackway midline (negative values for $F(3)=$ $4270.26379 * \beta_{p}+5.3169 * P_{p}(n)-24.0727$, see Table 7, Fig. 16). According to the linear discriminant 428 functions $F(1)$ and $F(2)$ the Maroon trackways and those from Tłumaczow/Poland and Marietta/Oklahoma are classified as Birkheide-Gottlob type.

As discussed above, neither the samples from Gottlob and Birkheide nor those from Haine's Farm and Alveley display a complete overlap in toe proportions and trackway parameters. Considering the small sample size (in terms of trackways per locality) their combination in the Birkheide-Gottlob and Hainesi-Willsi morphotypes has to be considered as a preliminary assessment. Thus, we have refrained from splitting "Ichniotherium with relatively short pedal digit V" into several ichnospecies - despite our interpretation that tracks assigned to the three morphotypes were produced by functionally distinct trackmakers. Our redefinition has also the benefit that the name Ichniotherium cottae can be preserved for the Bromacker sample as the best known and largest individual sample of such trackways. However, studies that make use of the Ichniotherium cottae data presented here or elsewhere should avoid their unreflecting inclusion as one homogeneous ichnospecies.

With the exception of the sparse record from the Ichniotherium cottae type locality Gottlob quarry, this approach includes only true trackways, i.e. series of imprints that constitute at least one complete step cycle. However, our analysis also found moderate differences in the toe proportions suggesting that imprint morphology yields information useful for the subdivision of Ichniotherium cottae. Given that other localities yield notable records of isolated imprints and imprint pairs (e.g., Czech Republic, Fritsch, 1887, Pabst, 1908; Morocco, Lagnaoui et al., in press; New Mexico, Voigt and Lucas, 2015, 2017b), imprint-morphologybased schemes could be tested through measurements on material not considered in the present approach and distributions for additional measures, such as angles between toes, total imprint width, length of the heel and depth in different parts of an imprint (which may be controlled by limb function, see Romano, Citton \& Nicosia 2016) could be gained. A feasible alternative to length-and-angle-based approaches would be a geometric morphometric analysis of imprint morphology. 
455 (4) Phylogenetic trends in the producer group

456 Age and morphology of the Gottlob-Birkheide type are intermediate between the Hainesi-Willsi 457 and Bromacker types of Ichniotherium cottae. Thus, evolution of trackmaker locomotion might 458 be inferred from changes in the trackmaker pattern from the earliest through the youngest 459 morphotype, i.e. in a stratigraphic approach (Fig. 17). However, we consider a phylogenetic 460 approach as better suited for a large geographically widespread set of individual ichnofossil 461 records as it allows the inclusion of further types of overlapping age in the future (e.g. for the 462 Maroon record). Furthermore, a phylogenetic hypothesis enables us to include Ichniotherium 463 sphaerodactylum and Ichniotherium praesidentis as an outgroup to the assemblage of Ichniotherium cottae morphotypes and to relate functional change inferred from tracks to diadectomorph phylogeny (Fig. 18).

Despite considerable differences between the Late Carboniferous Ichniotherium praesidentis from the German Ruhr area and the Early Permian representatives of Ichniotherium from the Thuringian Forest, the presence of five manual digits, general similarity of the pedal imprint morphology and large body size are in good agreement with the assignment of Ichniotherium praesidentis to diadectomorph producers (Voigt \& Ganzelewski, 2010). Following the hypothesis that the Ichniotherium praesidentis trackmaker either represents a member of diadectomorphs or another reptiliomorph group closely related to the Diadectomorpha-Amniota clade ('Cotylosauria' sensu Laurin \& Reisz, 1999), the occurrence of "Ichniotherium willsi", "Baropus hainesi" and "Megabaropus hainesi" in the Late Carboniferous of England and Ohio - which are referred to the Hainesi-Willsi type of Ichniotherium cottae here - marks a notable transformation in the trackway pattern from a presumably Ichniotheriumpraesidentis-like last ancestral state (Node A in Fig. 18): The increase in stride length and pace angulation occurs in combination with a decrease in trackway gauge width and apparent trunk length, reflecting an evolutionary change in early diadectomorph locomotion (evolutionary steps 1 and 2 in Fig. 18).

We have proposed that Ichniotherium with relatively short pedal digit $\mathrm{V}$ (ratio $\mathrm{V} / \mathrm{IV}<$ 0.6) - which has been synonymized with Ichniotherium cottae here - represents a monophyletic producer group (corresponding to Node C in Fig. 18) within Diadectidae and includes Late

484 Carboniferous and Permian taxa more closely related to Diadectes than Orobates (see also Fig. 2). The hypothetical track type of the last common ancestor of Diadectes and Orobates (corresponding to Node B in Fig. 18) can be assumed to display higher pace angulations, narrower gauges, higher stride lengths and more parallel-to-midline orientated manual imprints than Ichniotherium praesidentis (evolutionary step 1 in Fig. 18) but it might have shared the plesiomorphic condition of outward-rotated pedal imprints with Ichniotherium praesidentis and 
491 apparent trunk length might have been shared with Ichniotherium praesidentis and

492 Ichniotherium sphaerodactylum.

493 While average trackway gauge is comparatively narrow among all Ichniotherium cottae 494 tracks and the manual and pedal imprints of an imprint pair are consistently set at a low 495 distance along a trackway (evolutionary step 2, possible synapomorphies for Node C in Fig. 18), 496 several notable changes can be inferred when the three types of Ichniotherium cottae are 497 compared: The Permian Gottlob-Birkheide and Bromacker types can be distinguished from the 498 Late Carboniferous Willsi-Hainesi type by their parallel-to-midline orientation of pedal imprints 499 and slight inward rotation of manual imprints (evolutionary step 3, synapomorphy for Node D 500 in Fig. 18). Trackways of the best known last occurring type of Ichniotherium cottae from the 501 Bromacker locality display larger pace angulations and body-sized-normalized stride lengths 502 than all other considered Ichniotherium samples (evolutionary step 4 in Fig. 18). Apart from 503 differences in the trackway pattern, slight differences in the toe proportions occur (Figs. 12, 504 14A-B).

505 Pinpointing these changes among Ichniotherium cottae tracks to diadectid phylogeny is 506 mostly guesswork: If the assignment of the Bromacker Ichniotherium cottae to Diadectes 507 ("Silvadectes") absitus according to Voigt, Berman \& Henrici (2007) is correct, the trackmaker of 508 the Birkheide and Gottlob trackway occurrences could either be a functionally different relative 509 of $D$. absitus (a representative of the $D$. absitus lineage) or else a relative of the North American 510 Diadectes species (Diadectes sensu Kissel 2010) which was replaced by D. absitus in the 511 Thuringian forest area before the deposition of the Tambach Formation (stratigraphic level of 512 the Bromacker site). Trackmakers of the Willsi-Hainesi type might be found among 513 contemporaneous Late Carboniferous diadectid species, such as Desmatodon ("Sepeliodon") 514 hesperis or Diasparactus zenos (Reisz 2007, Kissel 2010; see Figs. 2, 18B).

$515 \quad$ Notable differences between the supposed lineages of Ichniotherium cottae and 516 Ichniotherium sphaerodactylum trackmakers are the latter's high apparent trunk length, 517 moderately wide gauge and relatively high distance between manual and pedal imprints of a 518 couple (no overstepping). Notwithstanding these characteristics Ichniotherium 519 sphaerodactylum reaches body-size-normalized pace lengths and stride lengths that can be 520 higher than in the Hainesi-Willsi and Gottlob-Birkheide types (see evolutionary step 5 in Fig. 521 16). Furthermore, Ichniotherium sphaerodactylum shares with the Gottlob-Birkheide and 522 Bromacker type tracks of Ichniotherium cottae a more inward rotation of the pedal and manual 523 imprints, a configuration that we consider as an independent parallel acquirement in both 524 lineages of Ichniotherium trackmakers.

525

526 (5) Functional implications 
527 Based on the comparison of average trackway patterns many aspects of the evolutionary 528 change in body shape, posture and locomotion from an Ichniotherium-praesidentis-like last 529 common ancestor of all Ichniotherium trackmakers towards the last common ancestor (and 530 earliest occurring specimens) of Ichniotherium cottae ("all Ichniotherium with relatively short 531 pedal digit V") trackmakers can be deduced (evolutionary steps 1 and 2 in Fig. 18): The 532 differences in gauge width, apparent trunk length and imprint orientations signify a decrease in 533 the degree of sprawling, a proportional shortening of the trunk and more inward rotation 534 (pronation) of the hands during ground contact. Higher strides ( $>20 \%$ increase in body-sizenormalized values) and notably higher pace angulations ( $>25^{\circ}$ increase) imply an increase in speed and general walking capability.

In the Early Permian Birkheide-Gottlob and Bromacker morphotypes of Ichniotherium cottae the inward orientation of the manual imprints is more pronounced than in the Late Carboniferous Haines-Willsi type and accompanied by a considerable parallel to inward orientation of pedal imprints, suggesting a further change in hindlimb posture (evolutionary step 3 in Fig. 18) following the earlier decrease in sprawling. Another change - the concurrent increase in stride length $(>10 \%)$, pace angulation $\left(>10^{\circ}\right)$, pace length and apparent trunk length towards the mid-Early Permian Bromacker type (evolutionary step 4 in Fig. 18) probably represents a further speed increase. Unlike the differences in apparent trunk length found between the Ichniotherium ichnospecies this particular increase is arguably not indicative for an actual increase in the trackmaker's trunk proportions but rather due to the correlation of speed, stride and apparent trunk length in otherwise similar trackmakers (see also dependence of stride and glenoacetabular length according to Leonardi, 1987). A conspicuous difference between the Bromacker type and other Ichniotherium cottae types does also occur in the imprint proportions: Relatively shorter pedal digits $\mathrm{V}$ and $\mathrm{I}$ and a shorter manual digit I in the Bromacker type might either be anatomically controlled, i.e. reflect actual variation in trackmaker toe proportions, or can be explained by reduced rotational movements of the autopodia on the ground or a changed center of rotation compared to earlier Ichniotherium cottae types.

Ichniotherium cottae and Ichniotherium sphaerodactylum from the Bromacker locality (see specimen UGKU 130 which features both types on the same slab) share higher normalized average pace and stride lengths than earlier Ichniotherium cottae types, indicating a convergent speed increase in the lineage of Ichniotherium sphaerodactylum trackmakers (evolutionary step 5 in Fig. 18) after the divergence of the two ichnospecies (node b), which we pinpoint to the Late Carboniferous Orobates-Diadectes split. The trackmakers of Bromacker Ichniotherium sphaerodactylum (i.e. Orobates and/or related diadectids) represent walkers with a somewhat 
564 of two diadectid trackmakers within derived locomotion capabilities but differences in body 565 shape and posture may be explained by different foraging strategies or occupation of different 566 (but overlapping) sub-environments (Marchetti, Voigt \& Santi, in press).

In sum we observe a clear pattern of evolutionary change in terrestrial gait within a) 568 diadectid trackmakers of Ichniotherium cottae as an ichnotaxon composed of different forms 569 that share a relatively short pedal digit $\mathrm{V}$ and b) Ichniotherium trackmakers as a whole. 570 Following an early phase of evolutionary change in posture and locomotion with a reduction in 571 the degree of sprawling, shortening of the trunk, slight pronation of the hands during ground 572 contact and somewhat higher walking speeds, the later transformation of the trackway pattern 573 towards a more pronounced inward orientation of the manual and pedal imprints indicates a 574 further change in posture which arises in combination with a further increase in walking speed.

Diadectid evolution is thought to have been shaped by adaptation to a herbivorous 576 lifestyle which is visible in the phylogenetic transformation of the skull towards higher ability of processing plant material, but also in the gaining of body sizes that are not matched by more basal carnivorous terrestrial tetrapods (Sues \& Reisz, 1998; Reisz \& Sues, 2000; Kissel, 2010, Reisz \& Fröbisch 2014). In conflict with a late or continuous increase in Ichniotherium trackmaker body size, the earliest occurrences from the Late Carboniferous and Carboniferous/Permian boundary include the largest individuals, i.e. Ichniotherium praesidentis from Bochum (pes length up to 200 mm; Voigt \& Ganzelewski, 2010; Schöllmann, Ganzelewski, Piecha, Salamon, Voigt \& Wrede, 2015), two tracks from Haine's Farm (147-186 mm) and the Marietta specimen (156-183 mm, see Supplemental S3). In this regard a herbivory-related body size increase in Late Carboniferous diadectomorphs might have been an evolutionary step that initiated later changes in locomotion or released constraints on terrestrial mobility, but it does not explain the further speed increase and postural change towards the medium-sized Bromacker diadectids (pes length 67-88 mm in the Bromacker type of Ichniotherium cottae, 82$136 \mathrm{~mm}$ in Ichniotherium sphaerodactylum; Voigt, Berman \& Henrici, 2007). Considering this study's focus on angle measurements, (dimensionless) length ratios and a certain group of Ichniotherium tracks, the question of body size evolution in trackmakers surrounding the origin of amniotes cannot be exhaustively dealt with here (and shall be discussed elsewhere).

It should be noted that phylogenetic and functional implications discussed above share the problems of our ichnotaxonomic assessments: They are based on a relatively low number of specimens per locality and on a limited number of localities (those with actual trackways of Ichniotherium and not only incomplete step cycles). Most of the trackways discussed here come from the Bromacker and Birkheide quarries close to the town of Tambach-Dietharz (Thuringian

598 forest). Problems with the classification of certain Ichniotherium samples from localities in the 599 United States and Poland suggest that a more complex picture will arise in the future with an 600 increasing non-European record and higher overall sample size. Some of our conclusions 
601 regarding the evolution of function depend on the hypothesis that Ichniotherium with relatively 602 short pedal digit $\mathrm{V}$ actually corresponds to a monophyletic group of diadectid producers which 603 share a short fifth pedal toe as a synapomorphy. Osteological data supporting alternative 604 scenarios of pedal toe reduction in diadectids would weaken our hypothesis of evolutionary 605 advance within the group of Ichniotherium cottae trackmakers.

606 In accordance with earlier phylogenetic approaches to tetrapod tracks (Carrano \& 607 Wilson, 2001; Wilson, 2005) our phylogenetic interpretation of Ichniotherium trackways relies 608 on synapomorphy-based and stratigraphy-based correlation assumptions in addition to direct 609 track-trackmaker correlation (Bromacker site). Following the idea that trackway data yield 610 information on tetrapod locomotion that cannot be deduced from skeletons, mapping trackway 611 data on a phylogenetic tree of trackmakers opens up a way to infer evolution of locomotion 612 styles and related functional traits - if the trackmaker identity can be assigned with confidence. 613 Arguably this way of reasoning about Paleozoic tetrapod tracks, especially the reconstruction of 614 ancestral states for discrete or continuous trackway characters (see e.g., Cunningham, Omland 615 \& Oakley, 1998), can help to solve questions of locomotion evolution surrounding the origin of 616 amniotes in the future.

617

618

\section{Conclusions}

619

Measurements of ten toe lengths and six independent trackway parameters have been carried out for a sample of 25 Ichniotherium trackways (69 step cycles) from nine localities. Based on locality-wise quantitative comparisons of these trackways, three morphotypes of "Ichniotherium with relatively short pedal digit V" - the Birkheide-Gottlob, Bromacker and Hainesi-Willsi type - have been distinguished and related to certain functionally distinct diadectid trackmakers more closely related to Diadectes than Orobates. Given the small overall sample size and remaining uncertainties in the distinction of the three types, we suggest the use of the ichnospecies Ichniotherium cottae (Pohlig, 1892) for all "Ichniotherium with relatively short pedal digit V". Including the three types of Ichniotherium cottae in a phylogenetic framework together with Ichniotherium sphaerodactylum and Ichniotherium praesidentis, a trend of evolutionary advance in locomotion from the last common ancestor of all Ichniotherium trackmakers to the last common ancestor of all Ichniotherium cottae producers and from the latter to the trackmakers of the mid-Early Permian Bromacker type can be deduced. Among others, evolutionary transformation in trackmaker locomotion is reflected by

634 the occurrence of more parallel to inward manual and pedal imprint orientations, more obtuse 635 pace angulations, narrower gauges, higher body-size-normalized pace lengths and higher body636 size-normalized stride lengths. Since they have mainly been inferred based on European 
637 trackways records, these changes might either represent a local signal or a more general 638 pattern of diadectomorph evolution.

639

640 Acknowledgements

641

642 We are thankful to Gottfried Böhme, Peter Cramer, Dale Gnidovec, Hartmut Haubold, Andrea 643 Heinke, Wolf-Dieter Heinrich, Jason Hilton, Dietrich von Knorre, Thomas Martens, Arnold 644 Niziołek, Gerd Riedel, Dieter Schweiss, Bryan Small, Hans-Detlef Stober, Glenn Storrs, Ralf 645 Werneburg and Frederick Voner for access to the specimens included in this analysis. Kirstin S. 646 Brink, Marco Romano, Peter Falkingham and Jens Lallensack are gratefully acknowledged for 647 their critical comments on an earlier version of this manuscript.

648

649

\section{References}

650

651

Baird D. 1952. Revision of the Pennsylvanian and Permian footprints Limnopus, Allopus and 652 Baropus. Journal of Paleontology 26:832-840.

653

654

Berman DS, Sumida SS, Martens T. 1998. Diadectes (Diadectomorpha: Diadectidae) from the 655 Early Permian of central Germany, with description of a new species. Annals of Carnegie 656 Museum 67:53-93.

657

658

Berman DS, Henrici AC, Kissel RA, Sumida SS, Martens T. 2004. A new diadectid 659 (Diadectomorpha), Orobates pabsti, from the Early Permian of Central Germany. Bulletin of 660 Carnegie Museum of Natural History 35:1-36.

661

662 Liu J, Bever GS. 2015. The last diadectomorph sheds light on Late Palaeozoic tetrapod 663 biogeography. Biology letters 11(5): 20150100.

664

Brink KS, Hawthorn JR, and Evans DC. 2012. New occurrences of Ichniotherium and 666 Striatichnium from the Lower Permian Kildare Capes Formation, Prince Edward Island, Canada: palaeoenvironmental and biostratigraphic implications. Palaeontology 55(5):1076-1090.

Carrano MT, Wilson JA. 2001. Taxon distributions and the tetrapod track record. Paleobiology 670 27(3): 564-582.

671

672 Carman E. 1927. Fossil footprints from the Pennsylvanian System in Ohio. Bulletin of the 673 Geological Society of America 38:385-396. 
674

675 Cotta B. 1848. Bruchstücke. Neues Jahrbuch für Mineralogie, Geologie und Paläontologie

676 1848:133-134. [German]

677

678 Cunningham CW, Omland KE, and Oakley TH. 1998. Reconstructing ancestral character

679 states: a critical reappraisal. Trends in Ecology and Evolution 13(9): 361-366.

680

681

Fritsch A. 1887. [Giant Permian tetrapod footprints]. Vesmír 16: 121-122. [Czech]

682

683

Fritsch A. 1895. Über neue Wirbeltiere aus der Permformation Böhmens nebst einer Übersicht

684 der aus derselben bekannt gewordenen Arten. Sitzungsberichte der Königlich Böhmischen

685 Gesellschaft der Wissenschaften, Mathematisch-Naturwissenschaftliche Klasse 52:1-17. 686 [German]

687

688

Fritsch A. 1901. Die Fauna der Gaskohle und der Kalksteine der Permformation Böhmens.

689

Rivnac, Prag, 101 pp. [German]

690

691

Fritsch A. 1912. Studien im Gebiete der Permformation Böhmens. Archiv für die

692

Naturwissenschaftliche Landesdurchforschung von Böhmen 15:1-52. [German]

693

694

Hammer $\varnothing$, Harper DAT, Ryan PD. 2001. PAST: Paleontological Statistics software package for education and data analysis. Palaeontologica Electronica 4(1): 9 pp.

696

Haubold H. 2000. Tetrapodenfährten aus dem Perm - Kenntnisstand und Progress 2000. Hallesches Jahrbuch für Geowissenschaften B 22: 1-16. [German]

699

700

Haubold H, Sarjeant WAS. 1973. Tetrapodenfährten aus den Keele und Enville Groups (Permokarbon: Stefan und Autun) von Shropshire und South Staffordshire, Großbritannien. Zeitschrift für Geologische Wissenschaften 1: 895-933. [German]

703

704

Haubold H, Sarjeant WAS. 1974. Fossil vertebrate footprints and the stratigraphical correlation 705 of the Keele and Enville beds of the Birmingham Region. Proceedings of the Birmingham Natural History Society 22: 257-268.

707

Haubold H, Stapf H. 1998. The Early Permian tetrapod track assemblage of Nierstein, 
712 Kennedy NK. 2010. Redescription of the postcranial skeleton of Limnoscelis paludis Williston

713 Diadectomorpha, Limnoscelidae from the Upper Pennsylvanian of El Cobre Canyon, northern

714 New Mexico. New Mexico Museum of Natural History and Science Bulletin 49, 211-220.

715

716 Kissel RA. 2010. Morphology, Phylogeny, and Evolution of Diadectidae (Cotylosauria:

717 Diadectomorpha). University of Toronto, Ph.D. thesis.

718

719

Lagnaoui A, Voigt S, Belahmira A, Saber H, Klein H, Hminna A, Schneider JW. in press. Late

720

Carboniferous Tetrapod Footprints from the Souss Basin, Western High Atlas Mountains,

721

Morocco. Ichnos, DOI: 10.1080/10420940.2017.1320284

722

723

Laurin M, Reisz, RR. 1999. A new study of Solenodonsaurus janenschi, and a reconsideration of

724

amniote origins and stegocephalian evolution. Canadian Journal of Earth Sciences, 36:1239-

725 1255.

726

727

Leonardi G. 1987. Glossary and Manual of Tetrapod Footprint Palaeoichnology. Ministerio

728

Minas Energie, Departemento Nacional da Produçao Mineral, Brasilia.

729

730

Marchetti L, Voigt S, Santi G. in press. A rare occurrence of Early Permian tetrapod footprints:

731

Ichniotherium cottae and Ichniotherium sphaerodactylum on the same stratigraphic surface.

732 Ichnos

733

734

Pabst W. 1900. Beiträge zur Kenntniss der Thierfährten in dem Rothliegenden ,Deutschlands'

735

(I). Zeitschrift der Deutschen Geologischen Gesellschaft 52:48-63. [German]

736

737

Pabst W. 1908. Die Tierfährten in dem Rotliegenden Deutschlands. Nova Acta Leopoldina

738

89:315-481. [German]

739

740

Pohlig H., 1892, Altpermische Saurierfährten, Fische und Medusen der Gegend von 741 Friedrichroda in Thüringen; in Anonymous (ed.) Festschrift 70. Geburtstag von Rudolf Leuckardt. Leipzig, Engelmann, 59-64. [German]

743

744

Reisz RR. 2007. The cranial anatomy of basal diadectomorphs and the origin of amniotes; 228-

252 in Anderson JS, Sues H (eds.) Major Transitions in Vertebrate Evolution. Indiana University

746 Press, Bloomington. 
748 Reisz RR, Fröbisch J. 2014. The Oldest Caseid Synapsid from the Late Pennsylvanian of Kansas,

749 and the Evolution of Herbivory in Terrestrial Vertebrates. PLOS ONE 9(4): e94518.

750

751

Reisz RR, and Sues H-D. 2000. Herbivory in late Paleozoic and Triassic terrestrial vertebrates; 9-

752

41 in Sues HD (ed.) Evolution of Herbivory in Terrestrial Vertebrates: Perspectives from the

753

Fossil Record. Cambridge University Press, Cambridge, United Kingdom.

754

755

Romano M, Citton P. 2015. Reliability of digit length impression as a character of tetrapod

756

ichnotaxobase: considerations from the Carboniferous-Permian ichnogenus Ichniotherium.

757

Geological Journal 50(6): 827-838.

758

759

Romano M, Citton P, Nicosia U. 2016. Corroborating trackmaker identification through footprint

760

functional analysis: the case study of Ichniotherium and Dimetropus. Lethaia 49(1): 102-116.

761

762

Ruta M, Coates MI, Quicke, DL. 2003. Early tetrapod relationships revisited. Biological Reviews

763

78:251-345.

764

765

Ruta M, Coates MI. 2007. Dates, nodes and character conflict: addressing the lissamphibian

766

origin problem. Journal of Systematic Palaeontology 5: 69-122.

767

768

Schmidt H. 1956. Die große Bochumer Oberkarbon-Fährte. Paläontologische Zeitschrift 30:

769 199-206. [German]

770

771

Schöllmann L, Ganzelewski M, Piecha M, Salamon M, Voigt S, Wrede V. 2015. Auf großem Fuße

772

- die älteste Tetrapodenfährte Deutschlands. Archäologie in Westfalen-Lippe 6:23-25. [German]

773

774

Sues H-D, Reisz RR. 1998. Origins and early evolution of herbivory in tetrapods. Trends in

775 Ecology and Evolution 13 (4):141-145.

776

777

Voigt S. 2005. Die Tetrapodenichnofauna des kontinentalen Oberkarbon und Perm im Thüringer

778 Wald-Ichnotaxonomie, Paläoökologie und Biostratigraphie. Göttingen, Cuvillier Verlag, 305 p.

779 [German]

780

781

Voigt S. 2007. Auf den Spuren der Saurier: Die Tetrapodenfährten aus dem Oberkarbon und

782 Unterperm des Saar-Nahe-Beckens; 288-303 in Schindler T, Heidtke UHC (eds.) Kohlesümpfe,

783 Seen und Halbwüsten-Dokumente einer rund 300 Millionen Jahre alten Lebewelt zwischen

784 Saarbrücken und Mainz. Bad Dürkheim, Pollichia. [German] 
Voigt S, 2012. Fossilführung und Stratigraphie: Tetrapodenfährten im Rotliegend. Schriftenreihe der Deutschen Gesellschaft für Geowissenschaften 61:161-175. [German]

788

Voigt S, Berman DS, Henrici AC. 2007. First well-established track-trackmaker association of Paleozoic tetrapods based on Ichniotherium trackways and diadectid skeletons from the Lower Permian of Germany. Journal of Vertebrate Paleontology 27: 553-570.

792

Voigt S, Ganzelewski M. 2010. Toward the origin of amniotes: Diadectomorph and synapsid footprints from the early Late Carboniferous of Germany. Acta Palaeontologica Polonica 55 (1): 57-72.

796

Voigt S, Haubold H. 2000. Analyse zur Variabilität der Tetrapodenfährte Ichniotherium cottae aus dem Tambacher Sandstein (Rotliegend, Unterperm, Thüringen). Hallesches Jahrbuch für Geowissenschaften B 22: 17-58. [German]

800

Voigt S, Lucas SG. 2015. On a diverse tetrapod ichnofauna from Early Permian red beds in San Field Conference, Geology of the Meadowlands, Las Vegas Region, 241-252.

804

Voigt S, Lucas SG. 2017. Outline of a Permian tetrapod footprint ichnostratigraphy. In: Lucas, SG, Shen SZ (eds.) The Permian Timescale. Geological Society, London, Special Publications, 450, http://doi.org/10.1144/SP450.10.

808

Voigt S, Lucas SG. in press. Early Permian tetrapod footprints from central New Mexico. New Mexico Museum of Natural History and Science Bulletin

811

812 Voigt S, Lucas SG, Krainer K. 2013. Coastal-plain origin of trace-fossil-bearing red beds in the 813 Early Permian of southern New Mexico, U.S.A. Palaeogeography, Palaeoclimatology, 814 Palaeoecology 369:323-334.

815

816 Voigt S, Niedzwiedzki G, Raczynski P, Mastalerz K, Ptaszynski T. 2012. Early Permian tetrapod 817 ichnofauna from the Intra-Sudetic Basin, SW Poland. Palaeogeography, Palaeoclimatology, 818 Palaeoecology 313-314:173-180.

819

820 Voigt S, Saber H, Schneider JW, Hmich D, Hminna A. 2011. Late Carboniferous - Early Permian 821 tetrapod ichnofauna from the Khenifra Basin, central Morocco. Geobios 44:309-407. 
822

823 Voigt S, Small B, Sanders F. 2005. A diverse terrestrial ichnofauna from the Maroon Formation

824 (Pennsylvanian-Permian), Colorado: Biostratigraphic and paleoecological significance. New 825 Mexico Museum of Natural History and Science Bulletin 30: 342-351.

826

827 Wilson JA. 2005. Integrating ichnofossil and body fossil records to estimate locomotor posture 828 and spatiotemporal distribution of early sauropod dinosaurs: a stratocladistic approach. 829 Paleobiology 31(3):400-423. 


\section{Table $\mathbf{1}$ (on next page)}

Structure of the trackway dataset.

Numbers refer to specimens, step cycles and imprint pairs (or individual imprints if only one of a pair is preserved; see also Supplemental S1). 


\begin{tabular}{|c|c|c|c|}
\hline Locality & Stratigraphy & Number & Previous assignment (author) \\
\hline $\begin{array}{l}\text { Gottlob/Friedrichroda, } \\
\text { Thuringia, Germany }\end{array}$ & $\begin{array}{l}\text { E. Permian (Asselian- } \\
\text { Sakmarian) }\end{array}$ & $8 / 2 / 12$ & I. cottae (Voigt, 2005) \\
\hline $\begin{array}{l}\text { Birkheide/Tambach, } \\
\text { Thuringia, Germany }\end{array}$ & $\begin{array}{l}\text { E. Permian } \\
\text { (Sakmarian -Artinskian) }\end{array}$ & $4 / 11 / 19$ & I. cottae (Voigt, 2005) \\
\hline $\begin{array}{l}\text { Bromacker/Tambach, } \\
\text { Thuringia, Germany }\end{array}$ & $\begin{array}{l}\text { E. Permian } \\
\text { (Artinskian) }\end{array}$ & $12 / 32 / 56$ & $\begin{array}{l}\text { I. cottae (Voigt \& Haubold, 2000; } \\
\text { Voigt 2005; Voigt, Berman \& } \\
\text { Henrici, 2007) }\end{array}$ \\
\hline $\begin{array}{l}\text { Haine's Farm, } \\
\text { Ohio, US }\end{array}$ & $\begin{array}{l}\text { L. Carboniferous } \\
\text { (Kasimovian-Gzhelian) }\end{array}$ & $2 / 9 / 13$ & $\begin{array}{l}\text { Megabaropus hainesi (Baird, } \\
\text { 1952) }\end{array}$ \\
\hline $\begin{array}{l}\text { Alveley/Shropshire } \\
\text { United Kingdom }\end{array}$ & $\begin{array}{l}\text { L. Carboniferous } \\
\text { (Moscovian- } \\
\text { Kasimovian) }\end{array}$ & $1 / 4 / 6$ & $\begin{array}{l}\text { I. willsi (Haubold \& Sarjeant, } \\
\text { 1973) }\end{array}$ \\
\hline $\begin{array}{l}\text { Maroon Formation, } \\
\text { Colorado, US }\end{array}$ & $\begin{array}{l}\text { L. Carboniferous } \\
\text { (Moscovian) - } \\
\text { E.Permian (Asselian) }\end{array}$ & $3 / 6 / 15$ & $\begin{array}{l}\text { l. cottae } 2005 \text { (Voigt, Small \& } \\
\text { Sanders, 2005) }\end{array}$ \\
\hline $\begin{array}{l}\text { Marietta, } \\
\text { Ohio, US }\end{array}$ & $\begin{array}{l}\text { L. Carboniferous } \\
\text { (Gzhelian) - E.Permian } \\
\text { (Asselian) }\end{array}$ & $1 / 3 / 5$ & $\begin{array}{l}\text { Ichniotherium cf. cottae } \\
\text { (unpublished) }\end{array}$ \\
\hline $\begin{array}{l}\text { Tłumaczow, } \\
\text { Poland }\end{array}$ & E. Permian (Sakmarian) & $1 / 2 / 4$ & I. cottae (Voigt et al., 2012) \\
\hline total & $\begin{array}{l}\text { Late Carboniferous } \\
\text { (Moscovian) - Early } \\
\text { Permian (Artinskian) }\end{array}$ & $32 / 69 / 130$ & 3 ichnospecies \\
\hline
\end{tabular}




\section{Table 2 (on next page)}

Averages of the normalized digit lengths and trackway measures for all localities. 
1 Table 2A. Averages of the normalized digit lengths for all localities, based on imprints with at least four 2 out of five digit lengths and pedal digit length IV measurably preserved.

3

\begin{tabular}{lccccccccc}
\hline Locality & $\mathrm{p}_{\mathrm{I}}(\mathrm{n})$ & $\mathrm{p}_{\| \mid}(\mathrm{n})$ & $\mathrm{p}_{\mathrm{III}}(\mathrm{n})$ & $\mathrm{p}_{\mathrm{V}}(\mathrm{n})$ & $\mathrm{m}_{\mathrm{I}}(\mathrm{n})$ & $\mathrm{m}_{\|}(\mathrm{n})$ & $\mathrm{m}_{\mathrm{II}}(\mathrm{n})$ & $\mathrm{m}_{\mathrm{IV}}(\mathrm{n})$ & $\mathrm{m}_{\mathrm{V}}(\mathrm{n})$ \\
\hline Gottlob & 0.506 & 0.651 & 0.833 & 0.540 & 0.356 & 0.521 & 0.681 & 0.829 & 0.423 \\
Birkheide & 0.416 & 0.651 & 0.836 & 0.506 & 0.375 & 0.503 & 0.638 & 0.766 & 0.371 \\
Bromacker & 0.350 & 0.614 & 0.814 & 0.473 & 0.285 & 0.586 & 0.753 & 0.910 & 0.461 \\
Haine's Farm & 0.493 & 0.646 & 0.892 & 0.536 & 0.366 & 0.528 & 0.689 & 0.774 & 0.416 \\
Alveley & 0.437 & 0.620 & 0.823 & 0.570 & 0.372 & 0.498 & 0.660 & 0.864 & 0.454 \\
Maroon (two & & & & & & & & & \\
individual sites) & 0.389 & 0.585 & 0.816 & 0.558 & 0.295 & 0.475 & 0.653 & 0.783 & 0.404 \\
$\quad$ Marietta & 0.437 & 0.669 & 0.822 & 0.488 & 0.356 & 0.500 & 0.647 & 0.825 & 0.471 \\
Tłumaczow & 0.402 & 0.584 & 0.831 & 0.589 & 0.298 & 0.543 & 0.684 & 0.856 & 0.498 \\
\hline
\end{tabular}

4

5 Table 2B. Averages of trackway measures for all localities.

6

\begin{tabular}{lcccccccc}
\hline Locality & $\alpha_{\mathrm{p}}$ & $\alpha_{\mathrm{m}}$ & $\beta_{\mathrm{p}}$ & $\beta_{\mathrm{m}}$ & $\mathrm{P}_{\mathrm{p}}(\mathrm{n})$ & $\mathrm{C}(\mathrm{n})$ & $\mathrm{S}_{\mathrm{p}}(\mathrm{n})$ & $\mathrm{B}_{\mathrm{p}}(\mathrm{n})$ \\
\hline Gottlob & 85.0 & 84.0 & 12.5 & 33.0 & 4.24 & 4.17 & 5.61 & 3.16 \\
Birkheide & 94.5 & 93.3 & 8.4 & 23.8 & 4.68 & 4.73 & 6.45 & 3.29 \\
Bromacker & 105.5 & 109.2 & 10.1 & 24.8 & 5.18 & 5.44 & 8.10 & 3.12 \\
Haine's Farm & 89.6 & 91.9 & -27.9 & 11.7 & 4.70 & 4.36 & 6.48 & 3.37 \\
Alveley & 102.3 & 92.0 & -13.5 & 6.3 & 4.67 & 5.26 & 7.27 & 2.92 \\
Maroon (two & & & & & & & & \\
sites) & 97.8 & 92.0 & -3.7 & 12.0 & 4.08 & 4.56 & 6.15 & 2.69 \\
Marietta & 107.7 & 102.0 & 3.0 & 9.0 & 4.53 & 5.06 & 7.38 & 2.64 \\
Tłumaczow & 106.0 & 90.0 & 1.0 & 34.5 & 4.29 & 5.12 & 6.80 & 2.63 \\
\hline
\end{tabular}




\section{Table 3(on next page)}

Multivariate analysis of variance (MANOVA) results documenting the distinctiveness of Thuringian Forest records according to different sets of toe ratios.

Null hypothesis that samples come from the same statistic population is not declined if $p$ value $>0.05$ ) 


\begin{tabular}{|c|c|c|c|c|}
\hline \multirow[t]{2}{*}{ Set of variables } & \multirow{2}{*}{$\begin{array}{l}\text { Wilk's lambda } \\
\text { test ( } p \text { value) }\end{array}$} & \multicolumn{3}{|c|}{ Hoteling test (Bonferroni-corrected $p$ values) } \\
\hline & & Brom vs Gott & Brom vs Birk & Gott vs Birk \\
\hline $\begin{array}{l}p_{1}(n) \text { to } p_{v}(n) \\
\text { sample size: } 27\end{array}$ & $4.579 * 10^{-6}$ & $8.27921 * 10^{-5}$ & 0.0232219 & 0.109217 \\
\hline $\begin{array}{l}\mathrm{m}_{\mathrm{l}} / \mathrm{m}_{\mathrm{IV}} \text { to } \mathrm{mV} / \mathrm{m}_{\mathrm{IV}} \\
\text { sample size: } 17\end{array}$ & 0.004365 & 0.588676 & 0.00295647 & 1 \\
\hline $\begin{array}{l}\left.p_{I}(n), p_{\| I} n\right), m_{1}(n), \\
m_{I V}(n) ; \text { sample: } 22\end{array}$ & $3.064 * 10^{-6}$ & 0.00995011 & 0.001823 & 0.14639 \\
\hline
\end{tabular}

1

2 


\section{Table 4 (on next page)}

Multivariate analysis of variance (MANOVA) results documenting the distinctiveness of Thuringian forest records.

Different sets of trackway parameters are tested.(Null hypothesis that samples come from the same statistic population is not declined if $p$-value $>0.05$.) 


\begin{tabular}{lcc}
\hline Set of variables & $\begin{array}{c}\text { Bromacker vs Birkheide } \\
\text { (Hoteling test } p \text { value) }\end{array}$ & $\begin{array}{c}\text { Bromacker vs Birkheide+Gottlob } \\
\text { (Hoteling test } p \text { value) }\end{array}$ \\
\hline $\begin{array}{l}\beta_{p}, \beta_{m}, C(n), P_{p}(n), \alpha_{m}, \alpha_{p} \\
\text { sample }=29 / 30\end{array}$ & $3.5855^{*} 10^{-6}$ & $1.90152 * 10^{-6}$ \\
$\begin{array}{l}C(n), P_{p}(n), \alpha_{m}, \alpha_{p} \\
\text { sample size: } 33 / 34\end{array}$ & $5.96582 * 10^{-9}$ & $3.00141 * 10^{-9}$ \\
$\beta_{p}, \beta_{m}, C(n), P_{p}(n), \alpha_{m}, \alpha_{p}$ & 0.04437 & 0.0181592 \\
sample size: $31 / 32$ & & \\
\hline
\end{tabular}

1

2 


\section{Table 5 (on next page)}

Multivariate analysis of variance (MANOVA) results documenting the distinctiveness of Ichniotherium samples from six localities.

Different sets of toe proportions are tested (null hypothesis that samples come from the same statistic population is not declined if $p$-value $>0.05$ ). For pairwise comparisons the Bonferroni-corrected $p$-values of Hotelling tests are listed. 


\begin{tabular}{lcccc}
\hline Test cases & $\begin{array}{c}p_{I}(n) \text { to } p_{V}(n) \\
\text { sample: } 41\end{array}$ & $\begin{array}{c}m_{\mathrm{I}} / \mathrm{m}_{\mathrm{IV}} \text { to } \mathrm{m}_{\mathrm{V}} / \mathrm{m}_{\mathrm{IV}} \\
\text { sample: } 25\end{array}$ & $\begin{array}{c}\mathrm{p}_{\mathrm{I}}(\mathrm{n}), \mathrm{p}_{\mathrm{II}}(\mathrm{n}), \mathrm{m}_{\mathrm{I}}(\mathrm{n}), \\
\mathrm{m}_{\mathrm{IV}}(\mathrm{n}) \\
\text { sample: } 40\end{array}$ & $\begin{array}{c}\mathrm{p}_{\mathrm{I}}(\mathrm{n}) \ldots \mathrm{m}_{\mathrm{IV}}(\mathrm{n}) \\
\text { Hain incl. Alve } \\
\text { sample: } 40\end{array}$ \\
\hline Total (p value for & $1.277^{*} 10^{-6}$ & 0.01946 & $8.252^{*} 10^{-9}$ & $1.425^{*} 10^{-8}$ \\
Wilk's lambda) & & & & \\
Brom vs Birk/Gott & 0.000472484 & 0.0417876 & 0.00123679 & 0.00101849 \\
Brom vs Hain & 0.00862805 & 0.344206 & 0.00436374 & 0.00319036 \\
Brom vs Alve & 0.0596709 & - & 1 & - \\
Brom vs Maro & 1 & 1 & 0.0475402 & 0.0585216 \\
Birk/Gott vs Hain & 0.405526 & 1 & 1 & 1 \\
Birk/Gott vs Alve & 1 & - & 1 & - \\
Birk/Gott vs Maro & 0.821683 & 1 & 0.0031644 & 0.00169635 \\
Hain vs Alve & 1 & - & 1 & - \\
Hain vs Maro & 0.920184 & 1 & 0.0111189 & 0.00155712 \\
Alve vs Maro & 1 & - & 0.729014 & - \\
\hline
\end{tabular}




\section{Table 6(on next page)}

Multivariate analysis of variance (MANOVA) results documenting the distinctiveness of Ichniotherium samples from six localities.

Different sets of trackway parameters are tested (null hypothesis that samples come from the same statistic population is not declined if $p$-value $>0.05$ ). For pairwise comparisons the Bonferroni-corrected p-values of Hotelling tests are listed. 


\begin{tabular}{lcccc}
\hline \multirow{2}{*}{ Test cases } & \multicolumn{2}{c}{ Alveley as separate sample } & \multicolumn{2}{c}{ Haine's Farm incl. Alveley } \\
\cline { 2 - 5 } & $\begin{array}{c}\beta_{p}, \beta_{m}, C(n), P_{p}(n), \\
\alpha_{p}, \alpha_{m} \\
\text { sample: } 49\end{array}$ & $\begin{array}{c}\alpha_{p}, \beta_{p}, P_{p}(n) \\
\text { sample: } 52\end{array}$ & $\begin{array}{c}\beta_{p}, \beta_{m}, C(n), P_{p}(n), \\
\alpha_{p}, \alpha_{m} \\
\text { sample: } 47\end{array}$ & $\begin{array}{c}\alpha_{p}, \beta_{p}, P_{p}(n) \\
\text { sample: } 52\end{array}$ \\
\hline total (p value for & $1.631 * 10^{-17}$ & $2.708^{*} 10^{-22}$ & $1.088^{*} 10^{-16}$ & $8.345^{*} 10^{-23}$ \\
Wilk's lambda) & & & & \\
Brom vs Birk/Gott & 0.00022799 & $1.35^{*} 10^{-6}$ & 0.000256636 & $8.14^{*} 10^{-7}$ \\
Brom vs Hain & $3.62 * 10^{-7}$ & $4.35^{*} 10^{-10}$ & $3.91 * 10^{-8}$ & $4.62 * 10^{-11}$ \\
Brom vs Alve & 0.00262849 & 0.00024067 & - & - \\
Brom vs Maro & $5.57^{*} 10^{-6}$ & $1.89 * 10^{-8}$ & $4.38^{*} 10^{-6}$ & $1.42^{*} 10^{-8}$ \\
Birk/Gott vs Hain & 0.0413744 & 0.000105081 & 0.00207178 & $8.04^{*} 10^{-6}$ \\
Birk/Gott vs Alve & 0.552279 & 0.0315482 & - & - \\
Birk/Gott vs Maro & 0.774264 & 0.0421465 & 0.441969 & 0.0264885 \\
Hain vs Alve & 1 & 1 & - & - \\
Hain vs Maro & 0.815793 & 0.0248551 & 0.173938 & 0.0048175 \\
Alve vs Maro & 1 & 0.554441 & - & - \\
\hline
\end{tabular}




\section{Table 7 (on next page)}

List of suggested discrimination criteria, each based on two variables (plus length of pedal digit IV).

Angles $(\alpha, \beta)$ shall be included with unit 'degree'. 


\begin{tabular}{lll}
\hline Discrimination steps & Linear Discriminant Function & Hotelling test \\
\hline (1) Brom vs. all others & $\mathrm{F}(1)=0.226^{*} \alpha_{\mathrm{p}}+7.786^{*} \mathrm{P}_{\mathrm{p}}(\mathrm{n})-60.405$ & $p=8.024^{*} 10^{-14}$ \\
$\begin{array}{l}\text { (2) Hain/Alve vs. } \\
\text { Birk/Gott/Maro }\end{array}$ & $\mathrm{F}(2)=0.30594^{*} \beta_{\mathrm{p}}-5.4972 * \mathrm{P}_{\mathrm{p}}(\mathrm{n})+27.8749$ & $p=1.718^{*} 10^{-7}$ \\
$\begin{array}{l}\text { (3) Birk/Gott vs Maro } \\
\text { (4) Maro vs. all others }\end{array}$ & $\mathrm{F}(3)=0.26379^{*} \beta_{\mathrm{p}}+5.3169^{*} \mathrm{P}_{\mathrm{p}}(\mathrm{n})-24.0727$ & $p=0.002283$ \\
$\begin{array}{l}\text { (5) Birk/Gott/Hain/Alve } \\
\text { vs. Brom }\end{array}$ & $\mathrm{F}(4)=20.402^{*} \mathrm{~m}_{\mathrm{IV}}(\mathrm{n})+35.512^{*} \mathrm{~m}_{\mathrm{l}}(\mathrm{n})-27.1769$ & $p=0.000195$ \\
\hline
\end{tabular}




\section{Table 8 (on next page)}

Discriminant function scores and classification of trackways from Tłumaczow/Poland and Marietta/Ohio. 


\begin{tabular}{lcccccccc}
\hline Specimen & Step Cycle & $\boldsymbol{\alpha}_{\mathbf{p}}$ & $\mathbf{P}_{\mathbf{p}}(\mathbf{n})$ & $\boldsymbol{\beta}_{\mathbf{p}}$ & $\mathbf{F ( 1 )}$ & $\mathbf{F ( 2 )}$ & $\mathbf{F ( 3 )}$ & Result \\
\hline MC-1 & 2 & 105 & 4.53 & 2 & -1.38 & 3.56 & 0.56 & B/G \\
MC-1 & 3 & 109 & 4.52 & 0 & -0.60 & 3.04 & -0.06 & Maroon \\
KGM-1 & 1 & 108 & 4.36 & -5 & -2.04 & 2.37 & -2.20 & Maroon \\
KGM-1 & 2 & 104 & 4.22 & 7 & -4.03 & 6.81 & 0.22 & B/G \\
\hline Specimen & Couple & $\mathbf{p}_{\mathbf{I}}$ & $\mathbf{p}_{\mathrm{V}}$ & $\mathbf{m}_{\mathbf{l}}$ & $\mathbf{m}_{\mathrm{IV}}$ & $\mathbf{F ( 4 )}$ & $\mathbf{F ( 5 )}$ & Result \\
\hline MC-1 & 2 & 0.47 & 0.49 & 0.30 & 0.81 & 0.17 & 2.03 & $\mathrm{~B} / \mathrm{G}+\mathrm{H} / \mathrm{W}$ \\
KGM-1 & 2 & 0.42 & 0.60 & 0.31 & 0.90 & 2.09 & 2.73 & $\mathrm{~B} / \mathrm{G}+\mathrm{H} / \mathrm{W}$ \\
KGM-1 & 3 & 0.41 & 0.60 & 0.26 & 0.85 & -0.37 & 2.68 & Maroon \\
KGM-1 & 4 & 0.38 & 0.57 & 0.32 & 0.81 & 0.88 & 0.64 & $\mathrm{~B} / \mathrm{G}+\mathrm{H} / \mathrm{W}$ \\
\hline
\end{tabular}




\section{Figure 1 (on next page)}

Ichnotaxonomic composition of IChniotherium and the variability in pedal toe lengths IV and $\mathrm{V}$ as a diagnostic criterion.

A, Histogram depicting the distribution of pedal digit ratios V/IV in Ichniotherium cottae from the Thuringian Forest (grey) and the other German records, I. sphaerodactylum and I. praesidentis (white). B, Distribution of I. sphaerodactylum, I. praesidentis, Ichniotherium cottae and further records of Ichniotherium in a plot of pedal digit length $V$ against pedal digit length IV (see Appendix 2). 

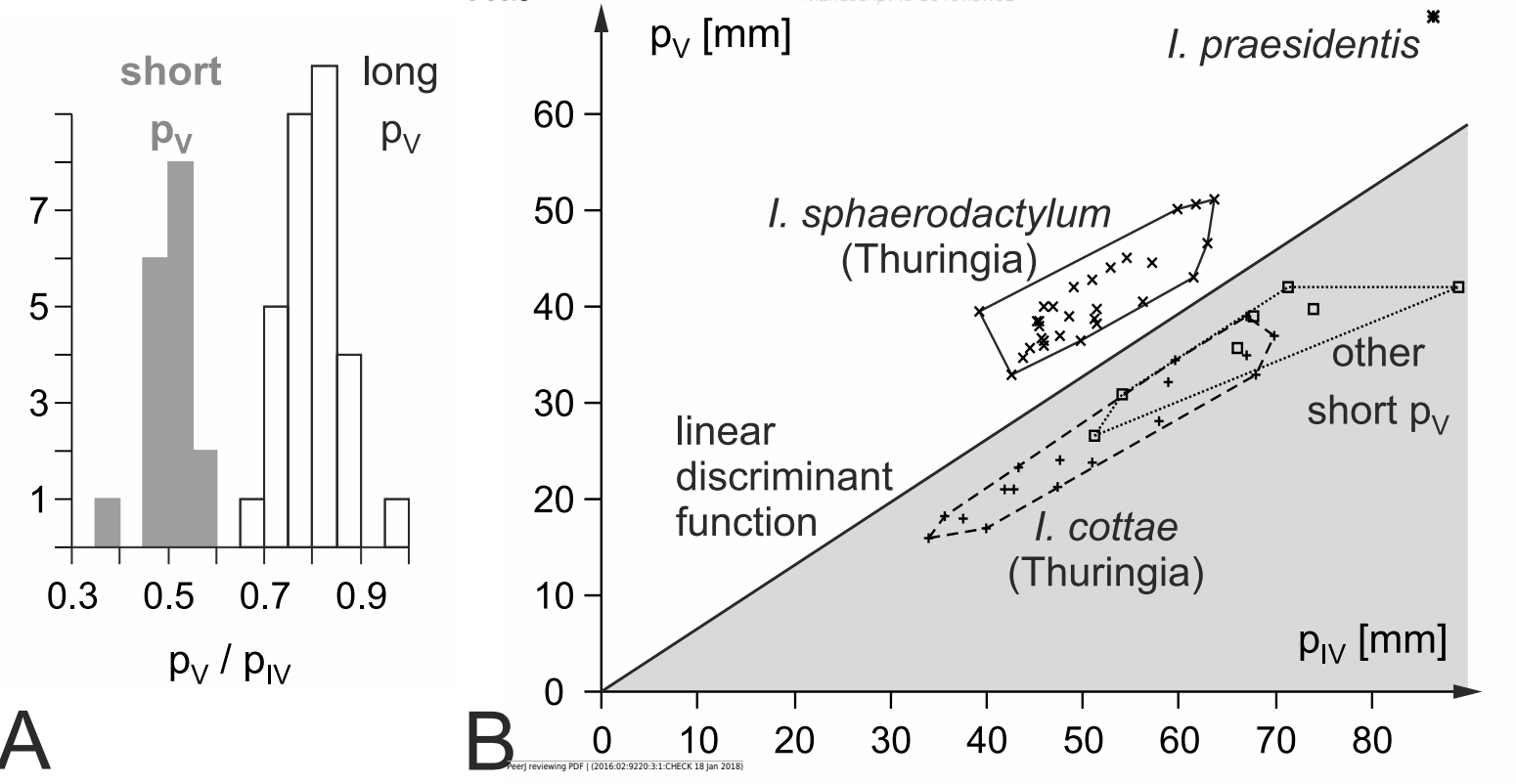
Figure 2 (on next page)

Fossil record of Ichniotherium trackways with relatively short pedal digit $\mathrm{V}$ and phylogeny of the Diadectomorpha within derived reptiliomorphs.

Localitiy abbreviations: A, Alveley; Bi, Birkheide; Br, Bromacker; G, Gottlob type locality; H, Haine's Farm; M, Maroon; Mt, Marietta; T, Tłumaczow. Modified after Reisz (2007), Kissel (2010) and Voigt \& Ganzelewski (2010). 


\section{Figure 3}

Ichniotherium cottae from the the Early Permian Goldlauter Formation (Gottlob locality, Thuringian Forest, Germany).

A, C - HF 57; B, D - HF 89; E, F MNG-1386; G, H - MNG-1781. Unlabeled scale bars equal 5 $\mathrm{cm}$.
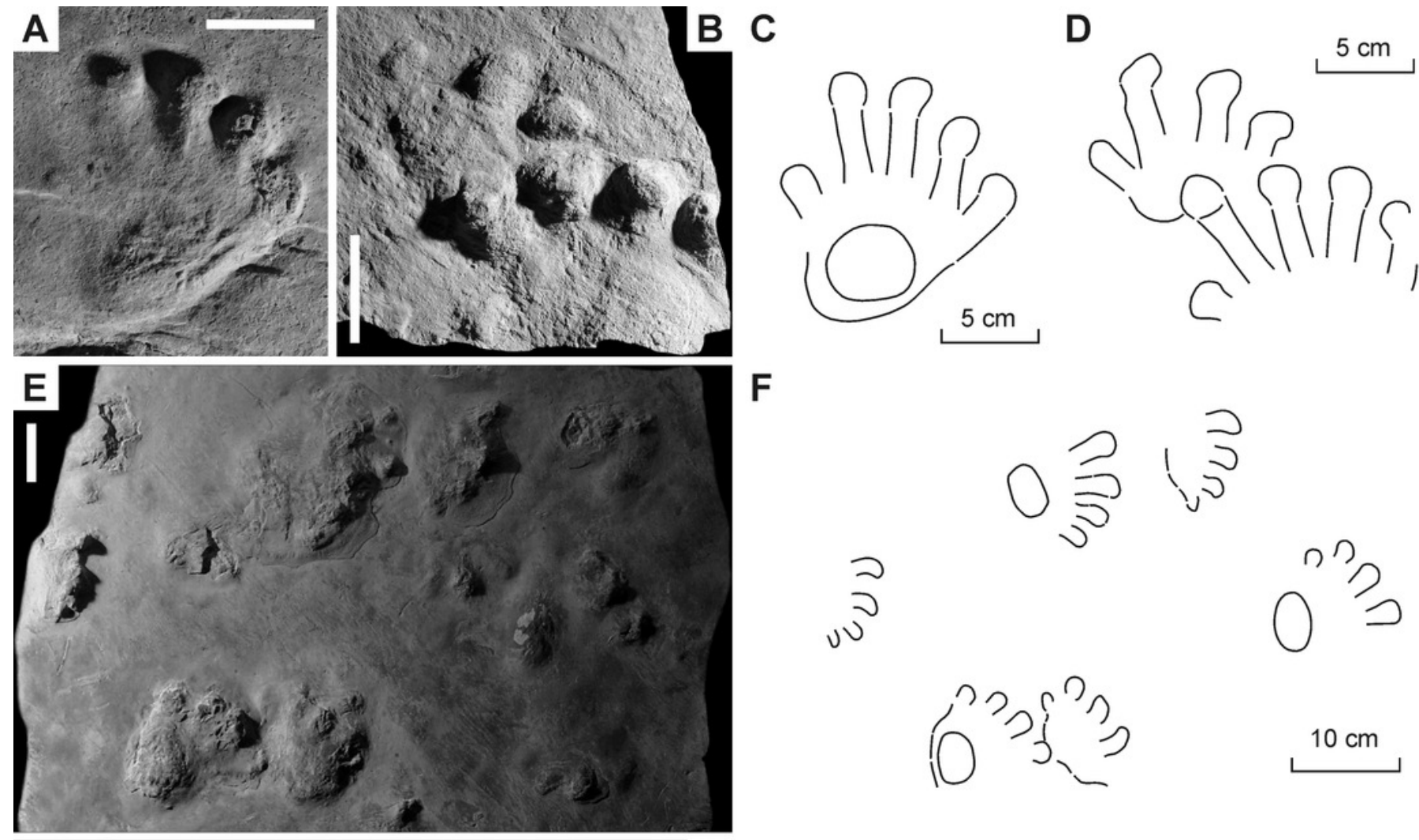

$F$
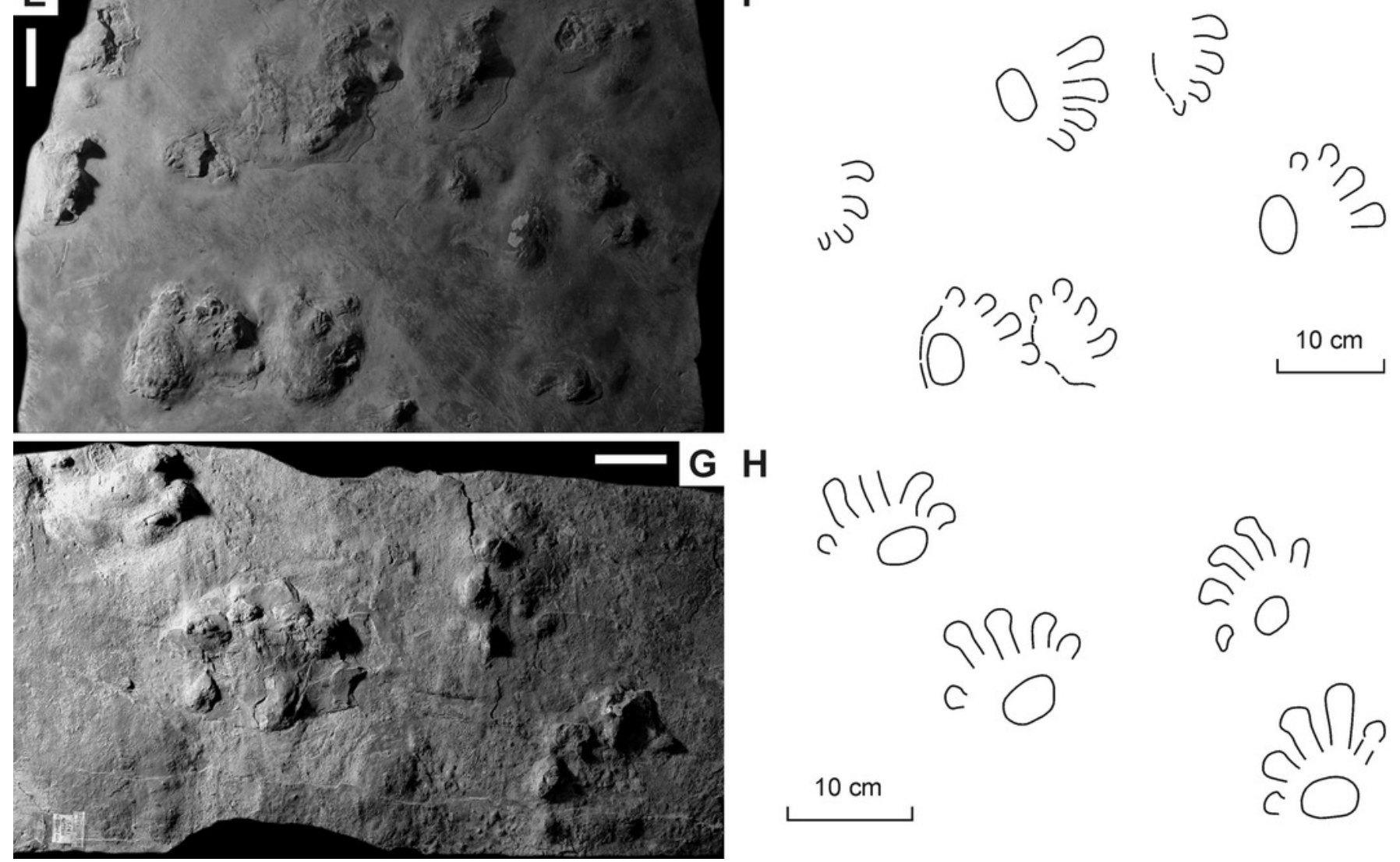

$10 \mathrm{~cm}$

aीก

c $\bigcirc$
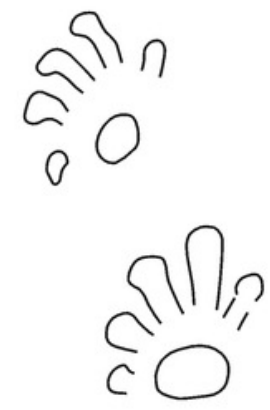
Figure 4

Ichniotherium cottae from the Early Permian Tambach Formation (Bromacker locality, Thuringian Forest, Germany).
A, D, G - MNG 1352; B, E, H - MB.ICV.3-1; C, F, I - SSB-1. Unlabeled scale bars equal $5 \mathrm{~cm}$ (A-
C) and $2 \mathrm{~cm}(D-F)$. 


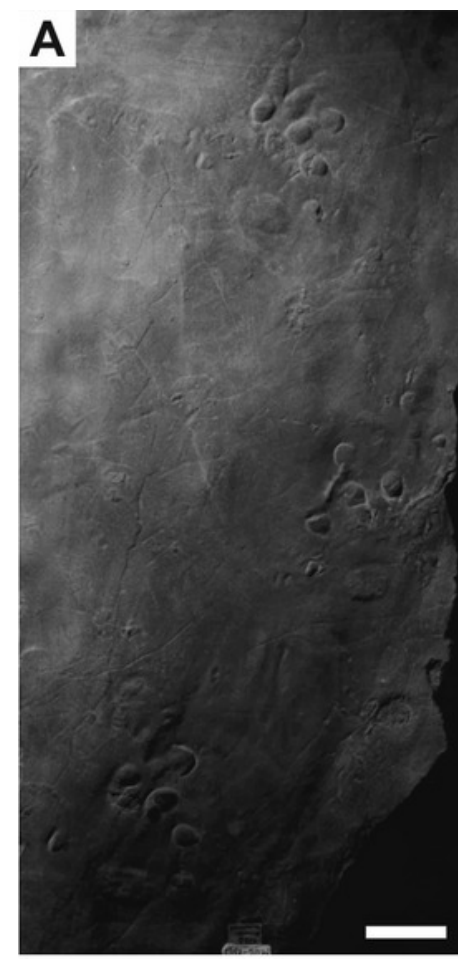

G

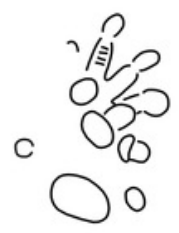

$5 \mathrm{~cm}$

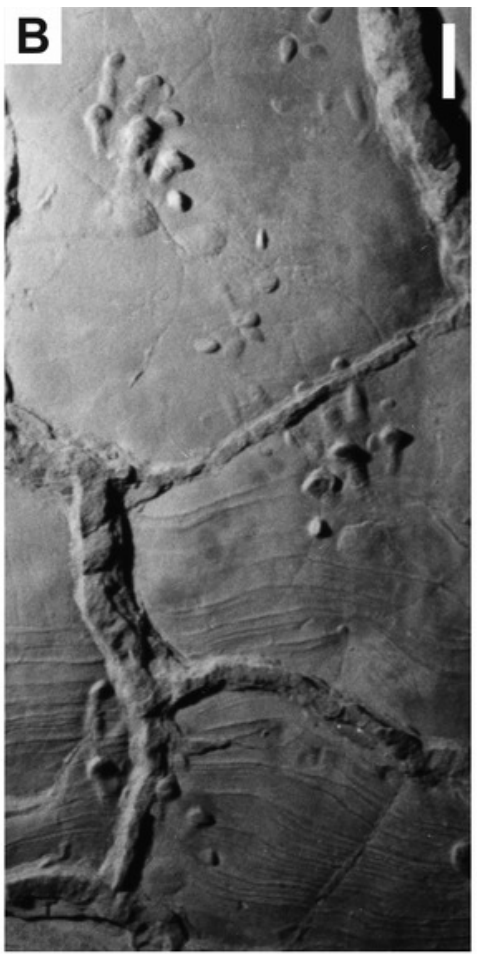

H

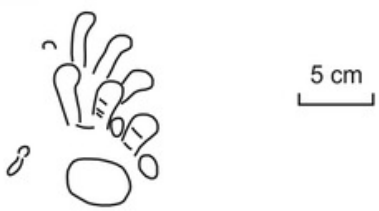

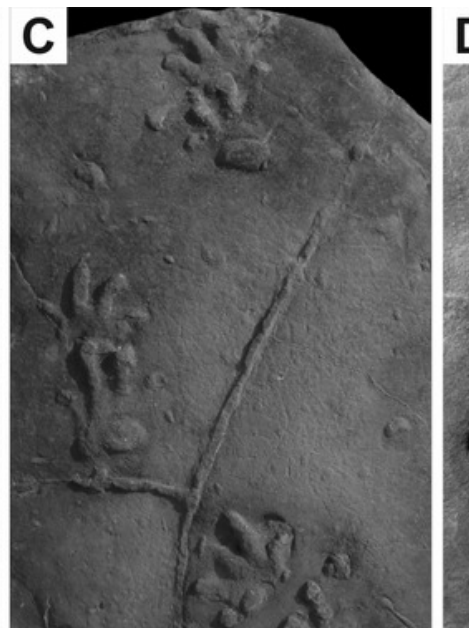
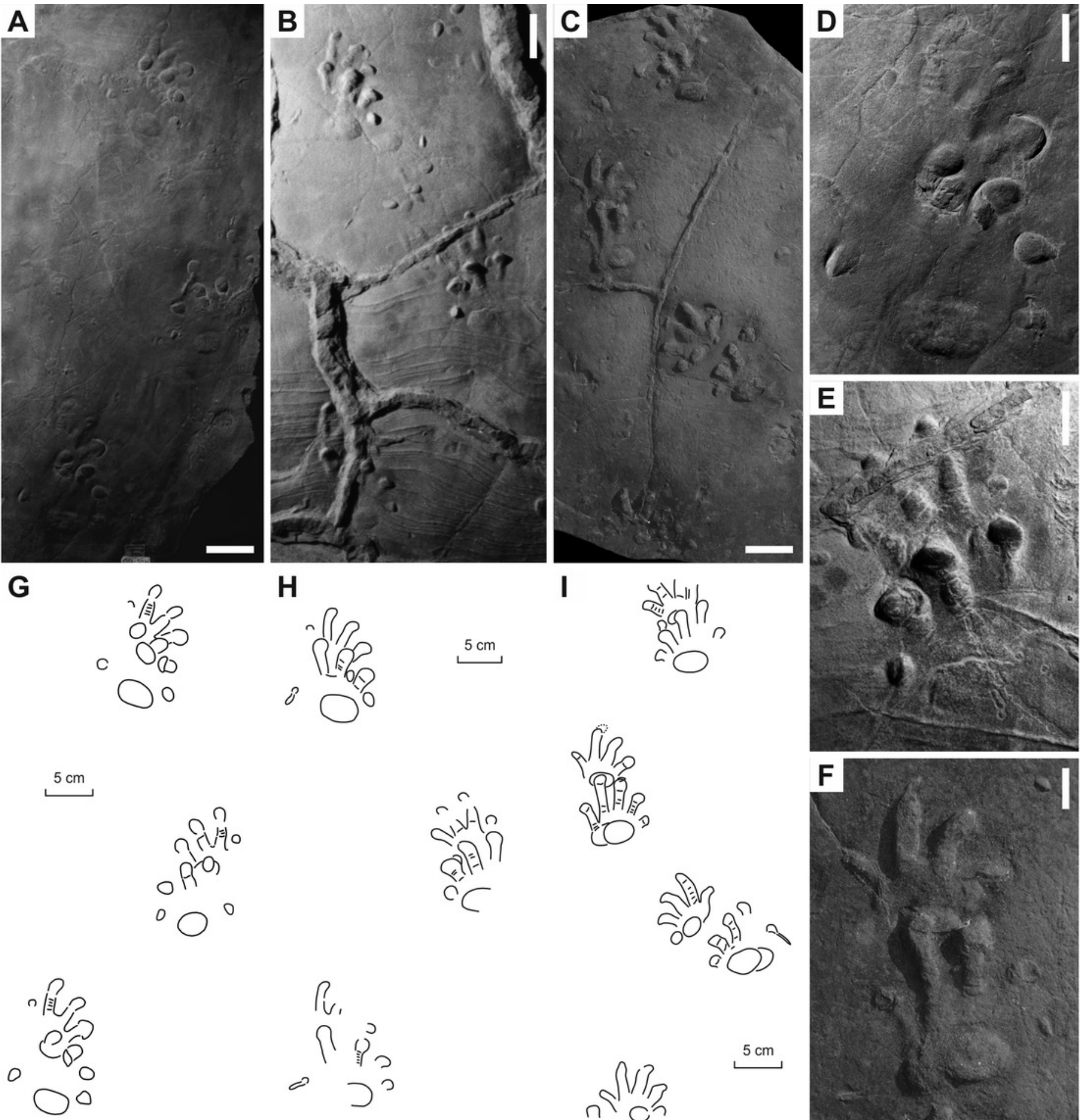
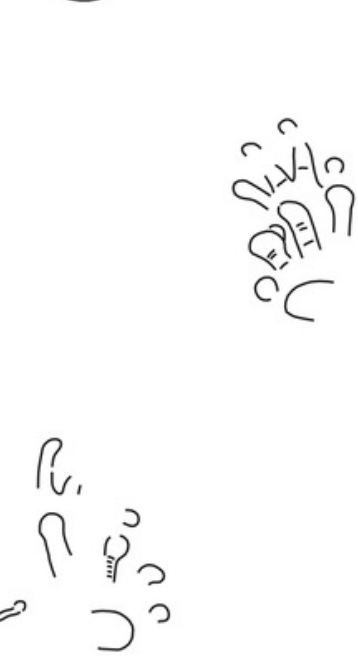

?

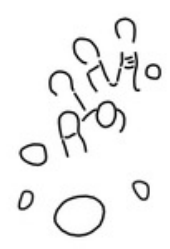

alders

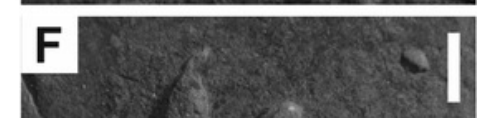


Figure 5

Ichniotherium cottae from the Early Permian Oberhof Formation (Birkheide locality, Thuringian Forest, Germany).

A, C - MNG 2049; B, D - NHMS AP-244-19. Unlabeled scale bars equal $5 \mathrm{~cm}$. 

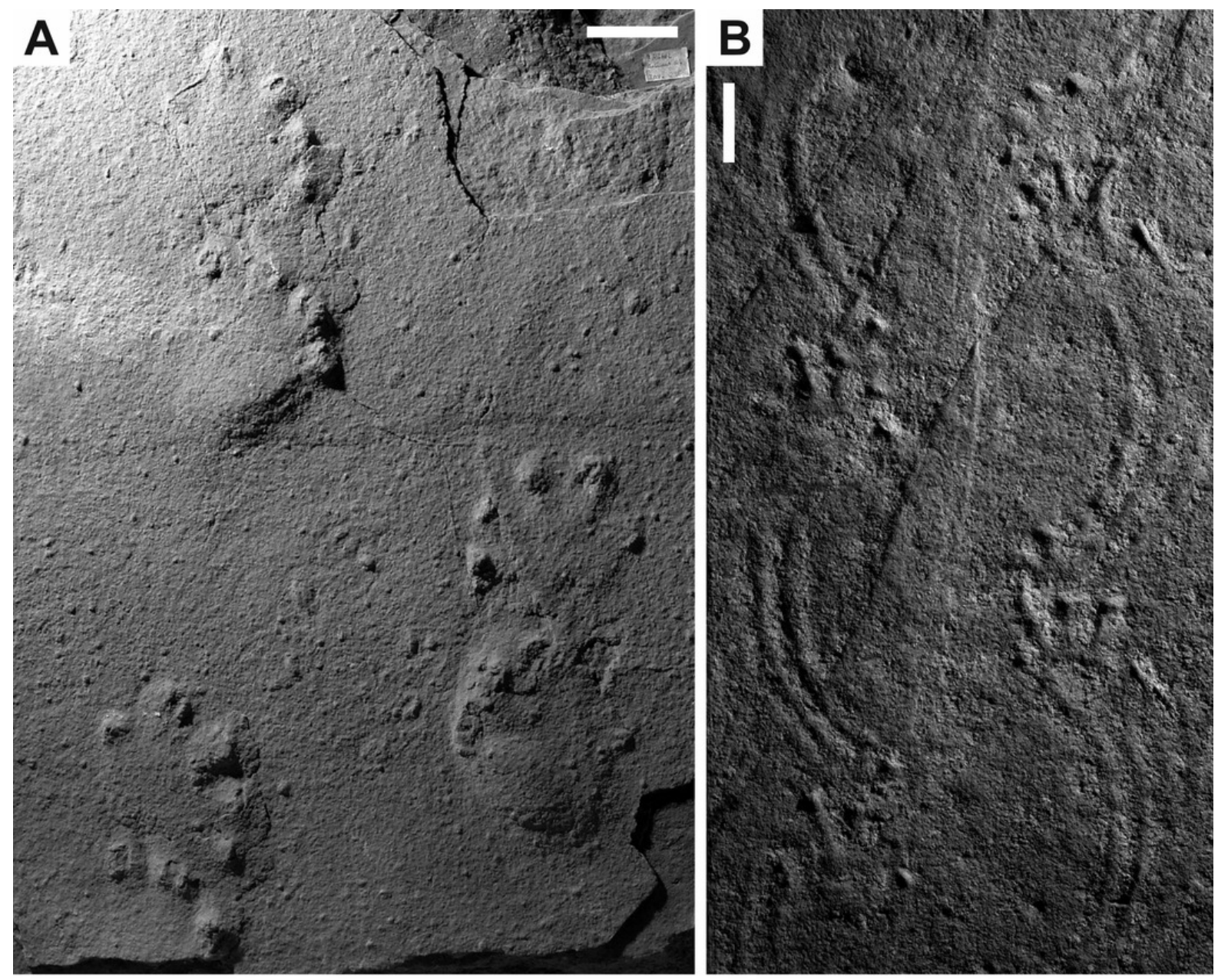

C

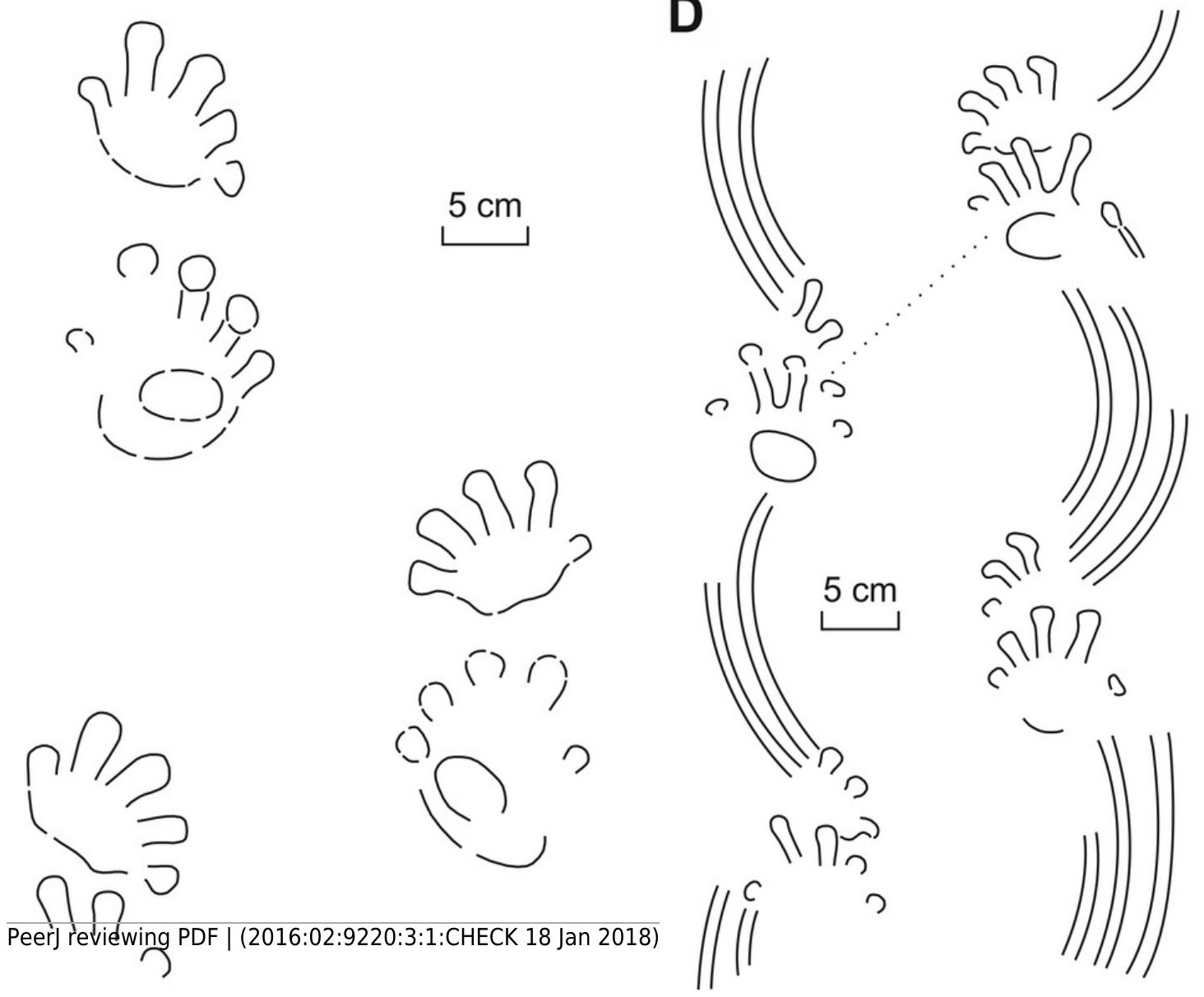




\section{Figure 6}

"Baropus hainesi" (Carman, 1927) (A, C) and "Megabaropus hainesi" (Baird, 1952) (B, D) from the Late Carboniferous Monongahela Group (Haine's Farm locality, Ohio, United States).

A, C - OSU 16553; B, D - CMNH VP-3052. Unlabeled scale bars equal $10 \mathrm{~cm}$.
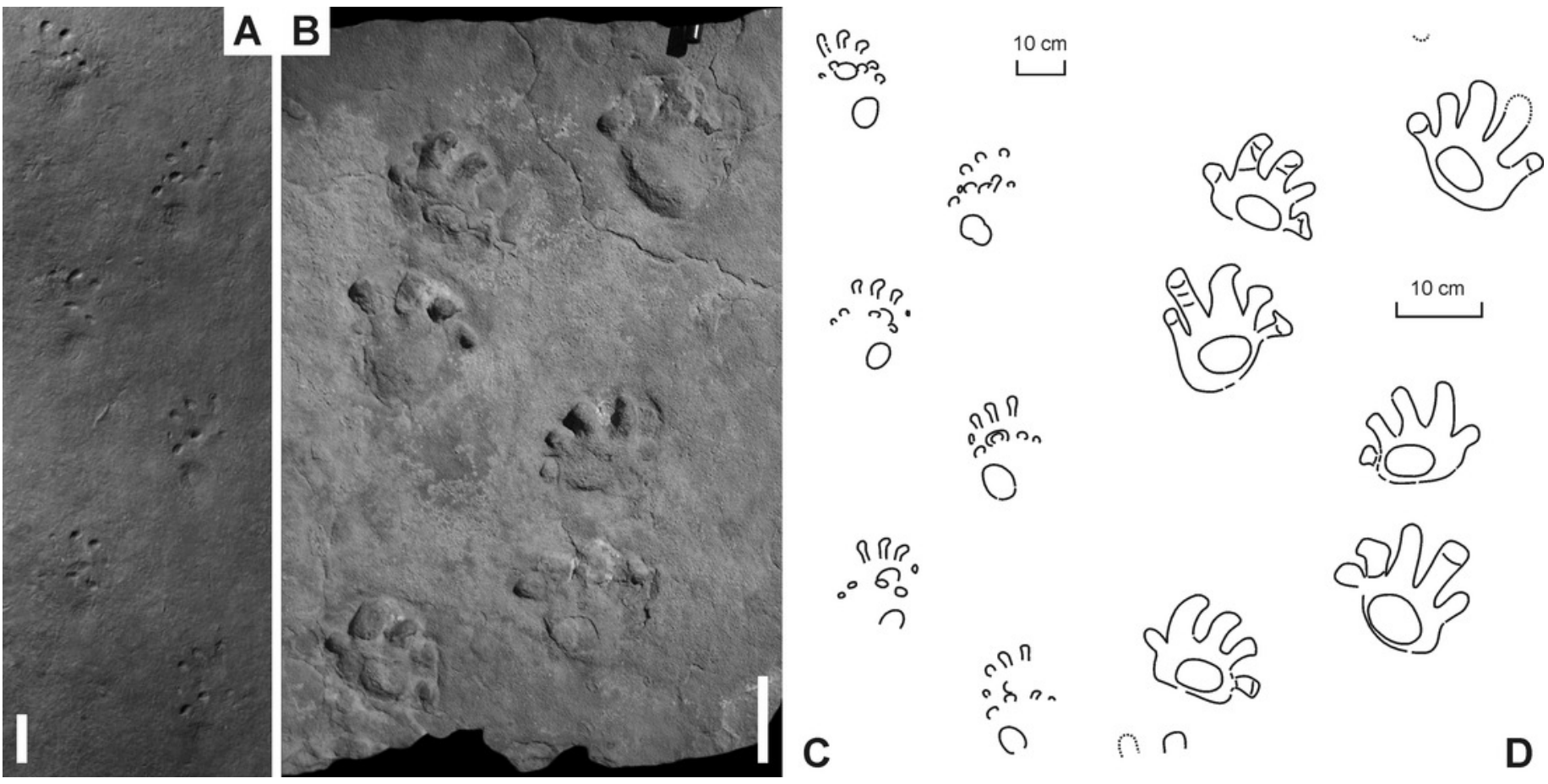

$c^{n}$ है?
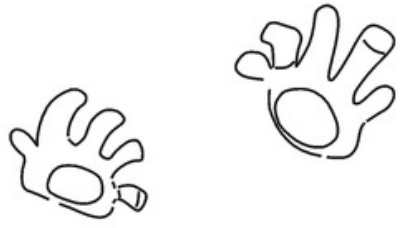

ก $\cap$

D 
Figure 7

"Ichniotherium willsi" (Haubold \& Sarjeant, 1973) from the Late Carboniferous Salop Formation (Alveley locality, Birmingham, United Kingdom).

A-D, BU 2471. Unlabeled scale bars equal $5 \mathrm{~cm}$. 

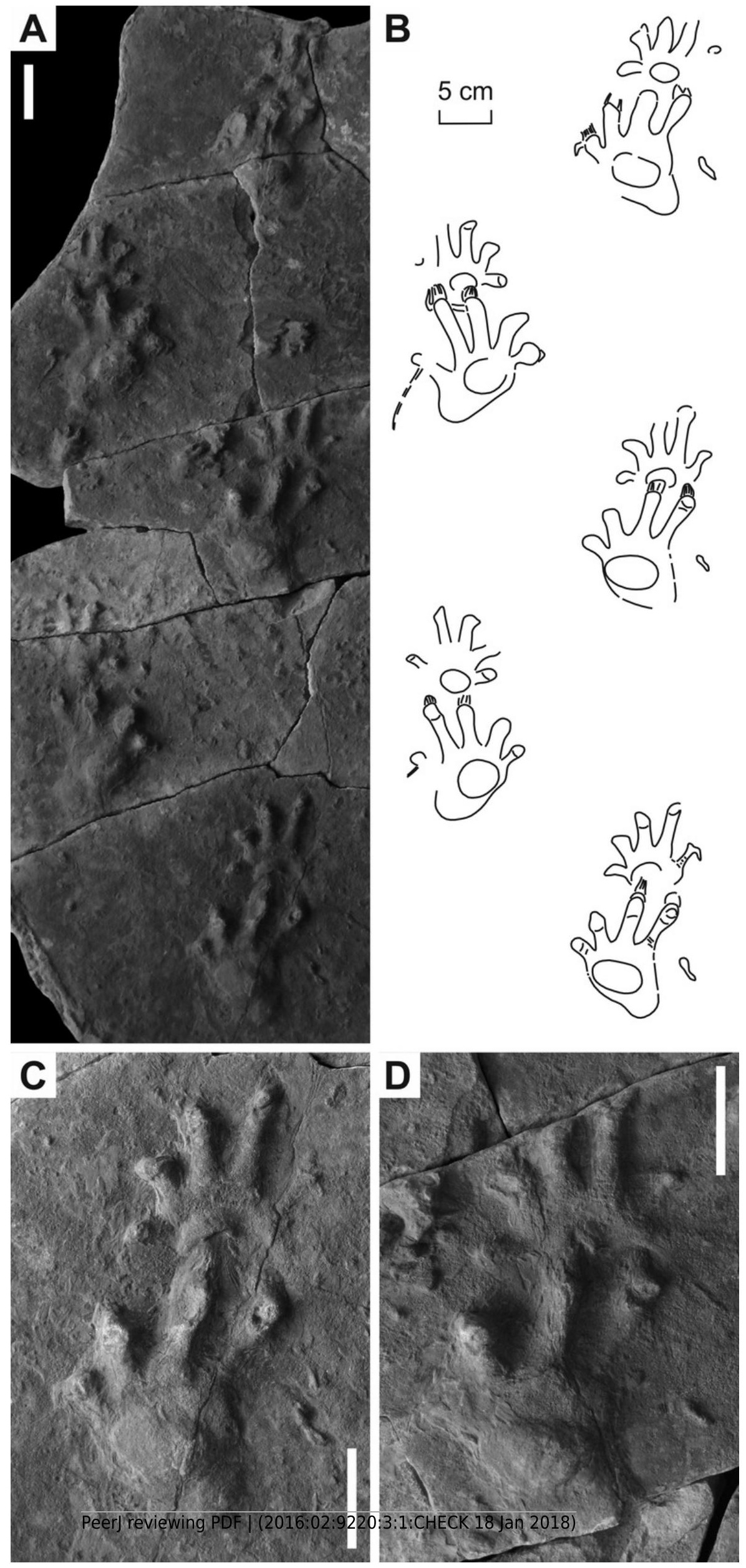
Figure 8

Ichniotherium isp. from the Early Permian Maroon Formation (Maroon localities, Colorado, United States).

A, D, G - DMNS 50618; B, E, H - DMNS 50622; C, F, I - DMNS 55056. Unlabeled scale bars equal $10 \mathrm{~cm}(\mathrm{~A}-\mathrm{C})$ and $5 \mathrm{~cm}(\mathrm{D}-\mathrm{F})$. 

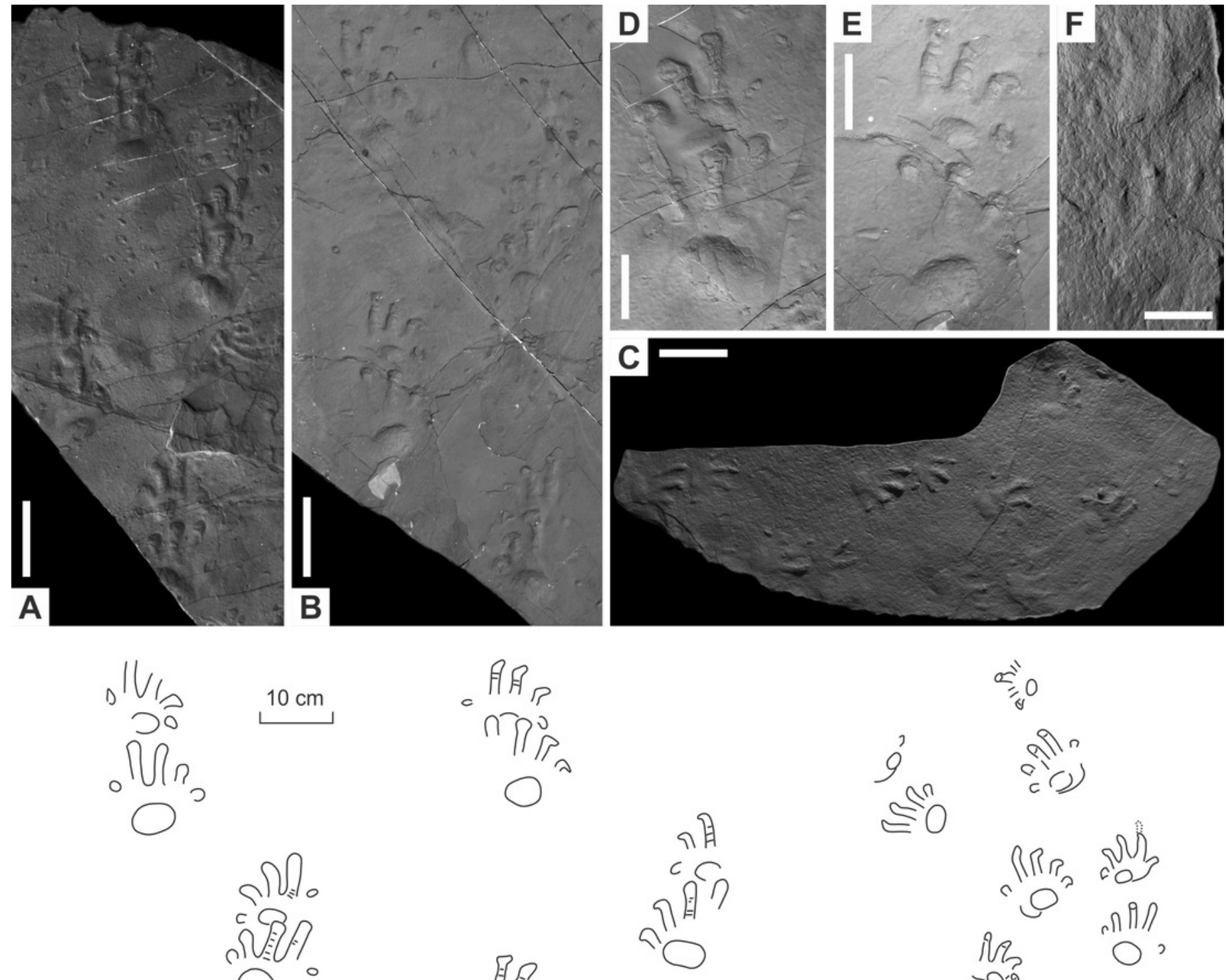

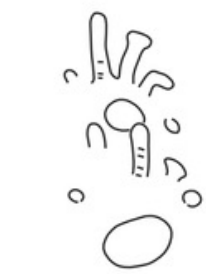

一睸
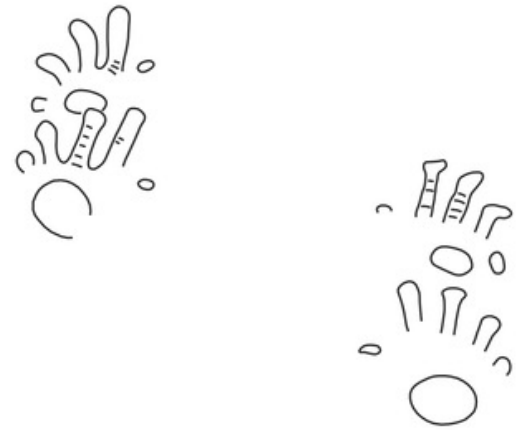

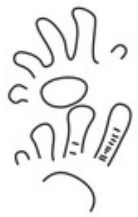

G

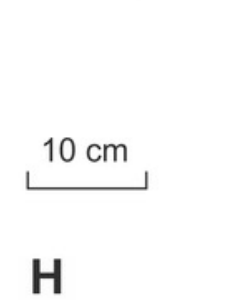

$$
\text { ल" }
$$$$
\begin{aligned}
& 9 \text { ब्रों } \\
& \text { जी की }
\end{aligned}
$$

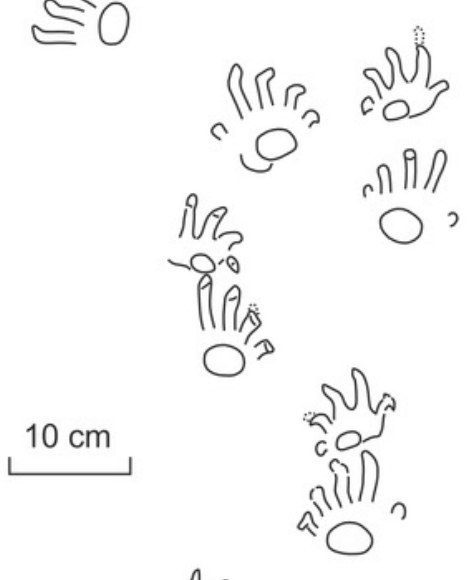

Sho

$\lim ^{2}$ 


\section{Figure 9}

Ichniotherium with relatively short $\mathrm{p}_{\mathrm{v}}$ from the Early Permian Washington Formation (Marietta locality, Washington County, Ohio).

A-D, MC-1. Unlabeled scale bars equal $10 \mathrm{~cm}(A)$ and $5 \mathrm{~cm}(B-C)$.
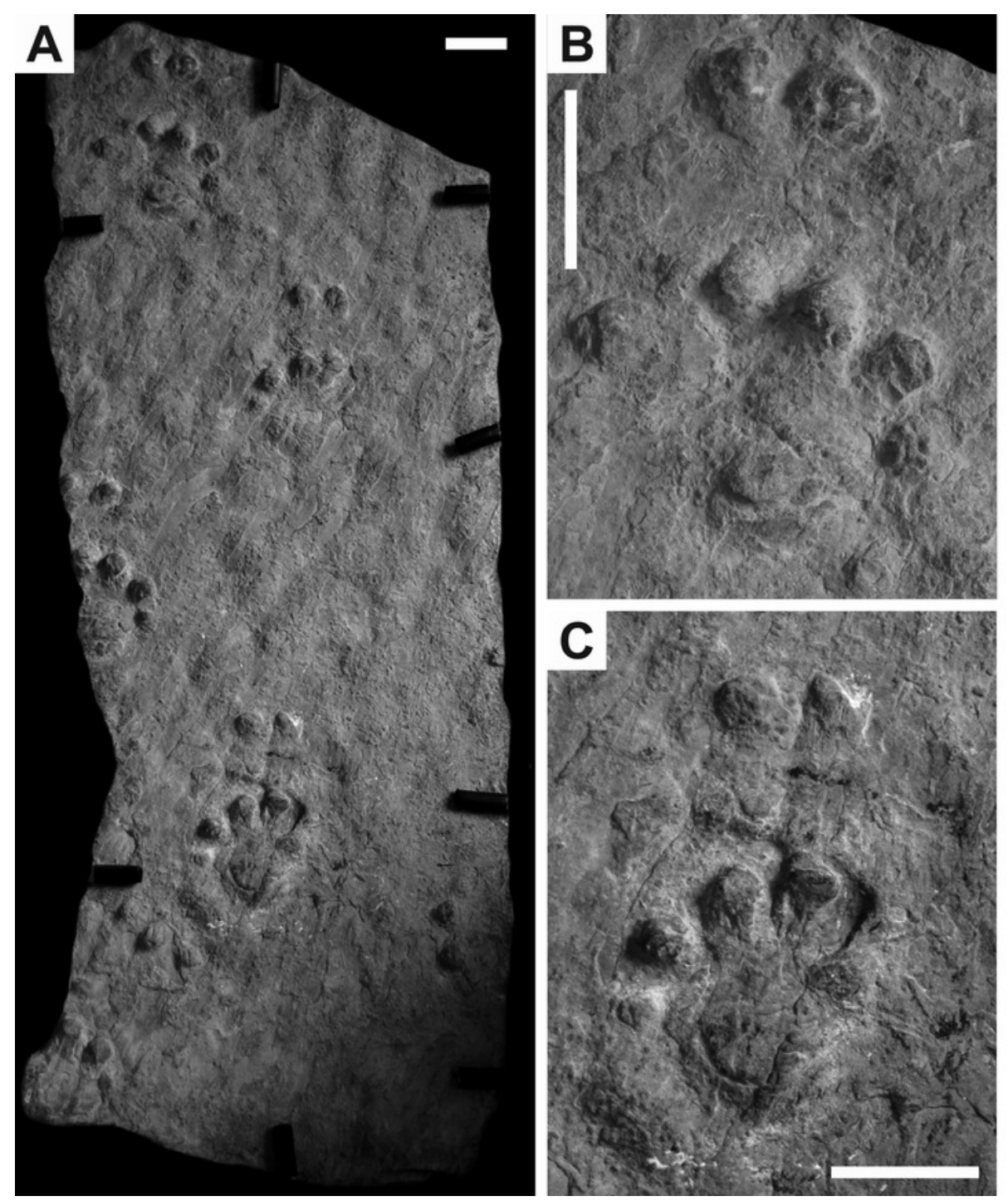

D<smiles>O=S1(=O)CCSCCO1</smiles>

$10 \mathrm{~cm}$
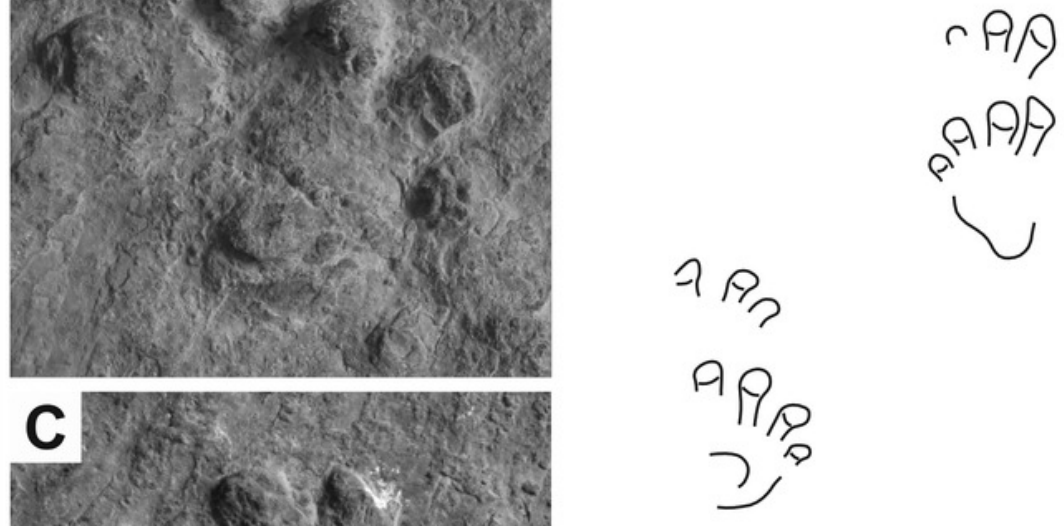

$7 \%$

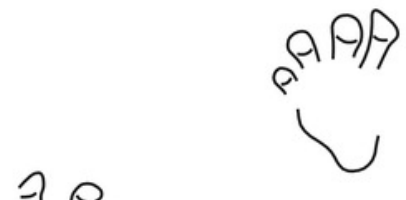

AP

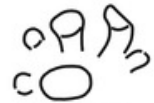

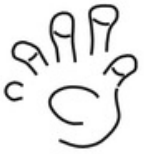




\section{Figure 10}

Ichniotherium with relatively short $\mathrm{p}_{\mathrm{v}}$ from the Early Permian Słupiec Formation (Tłumaczow locality, Kłodzko County, Poland).

A-D, KGM-1. Unlabeled scale bars equal $10 \mathrm{~cm}(\mathrm{~A})$ and $2 \mathrm{~cm}(\mathrm{~B})$.
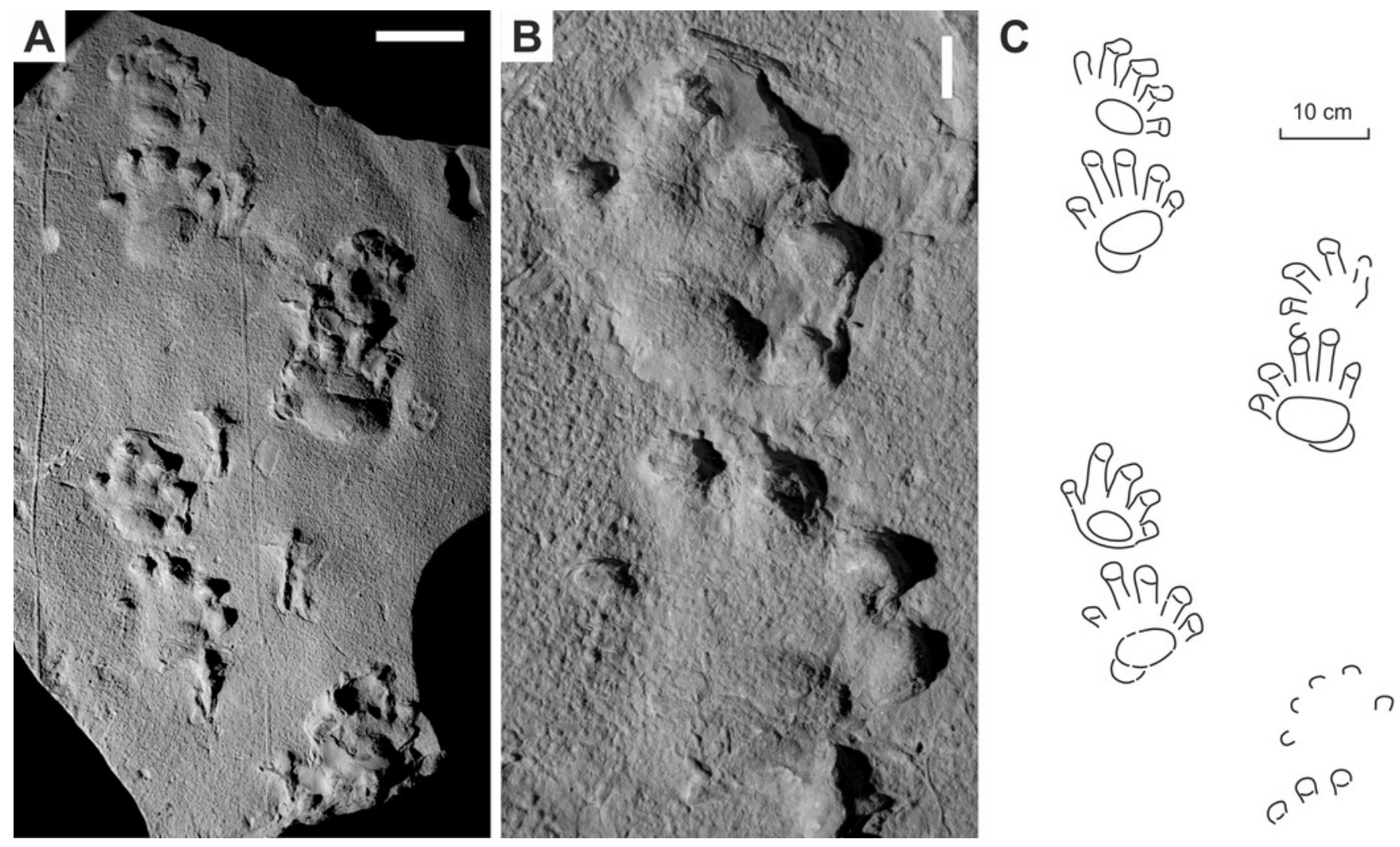


\section{Figure 11 (on next page)}

Imprint and trackway measures used in this approach.

$A$, Measures used in this approach include manual and pedal digit lengths $\left(m_{1}-p_{v}\right)$, pace angulation $(\alpha)$, imprint orientation $(\beta)$, apparent trunk length $(C)$, trackway width according to pedal sequence $\left(B_{p}\right)$, pedal stride length $\left(S_{p}\right)$ and pedal pace length $\left(P_{p}\right)$. B-D, Interpretation of toe tips (white crosses) and toe bases (black crosses) for three imprint pairs that belong to Ichniotherium specimens with varying states of preservation: B, BU 2471 (Salop Fm.); C, DMNS 50622(Maroon Fm.); D, MNG 1352 (Tambach Fm). In case of poorly preserved sole imprints the metering of free digit lengths relies on basal toe points inferred from the orientation of toes, the most clearly preserved toe basis and the outline of the heel pad (which is assumed to be parallel to the trendline connecting all toe bases). In many cases, however, some of the individual toe lengths cannot be determined and have to be considered as missing data. 


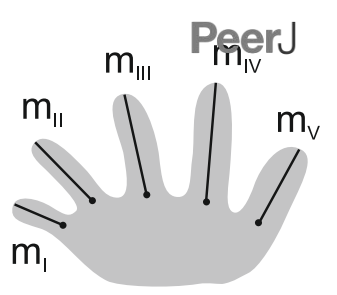

A
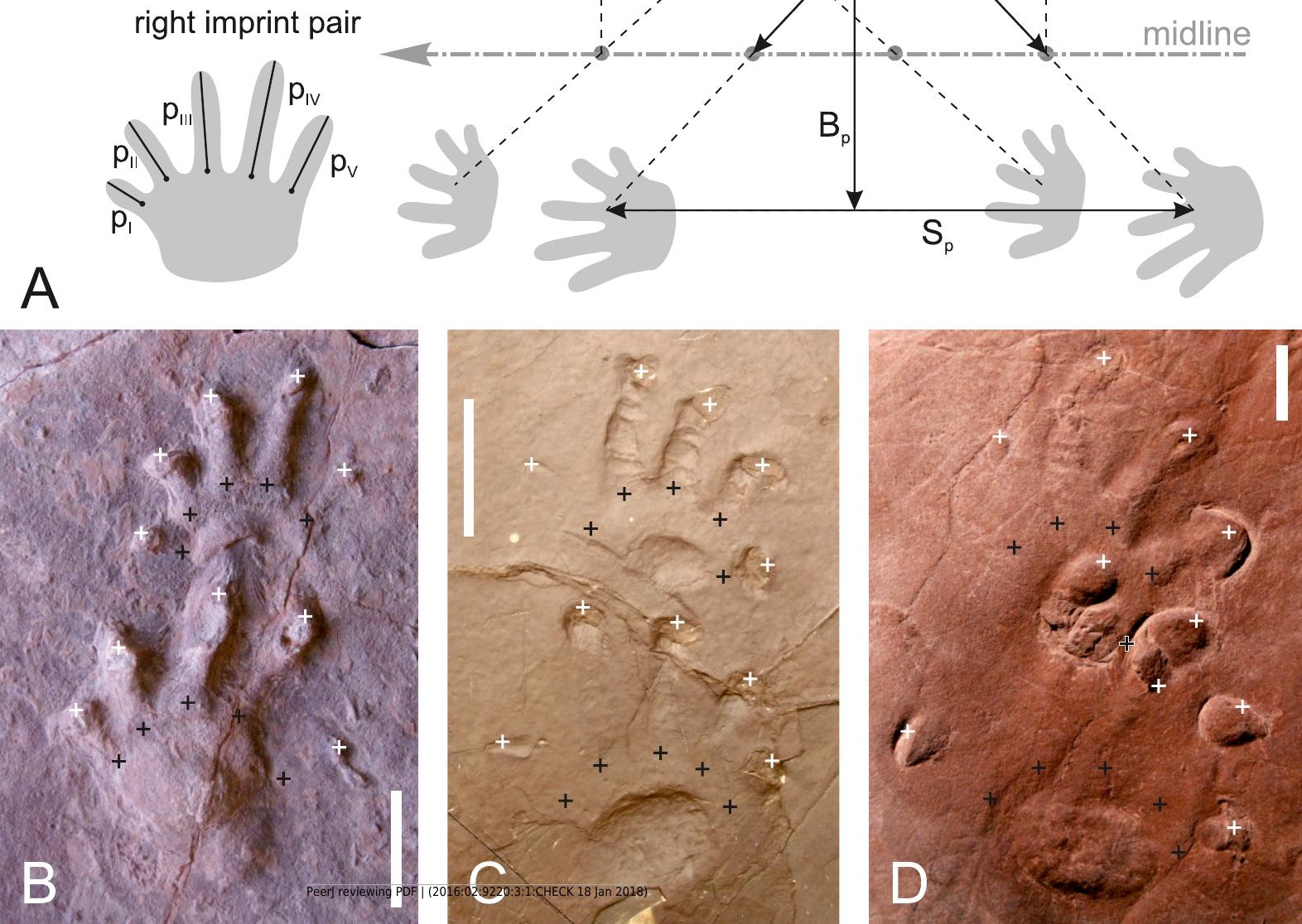
Figure 12 (on next page)

Variability in the toe ratios of Ichniotherium cottae from three Thuringian forest localities.

A, Biplot for a principal component analysis (PC 1 vs. 2) based on four manual toe rations, B, Biplot for a principal component analysis (PC 1 vs.2) based on four pedal imprint toe ratios. $D-E$, Toe ratio plots illustrate notable differences in imprint proportions between different Thuringian forest localities. 
Figure 13(on next page)

Variability in trackway parameters of Ichniotherium cottae from three Thuringian forest localities.

A, biplot for a Principal Component Analysis (PC 1 vs. 2) based on six variables. B, plot of manual vs. pedal pace angulation, C, manual vs. pedal imprint orientation; D, apparent trunk length (normalized) vs. pedal pace length (normalized), E, gauge width (normalized) vs. stride length (normalized), F, pedal pace length (normalized) vs. pedal pace angulation. Go step cycles from Gottlob quarry. 

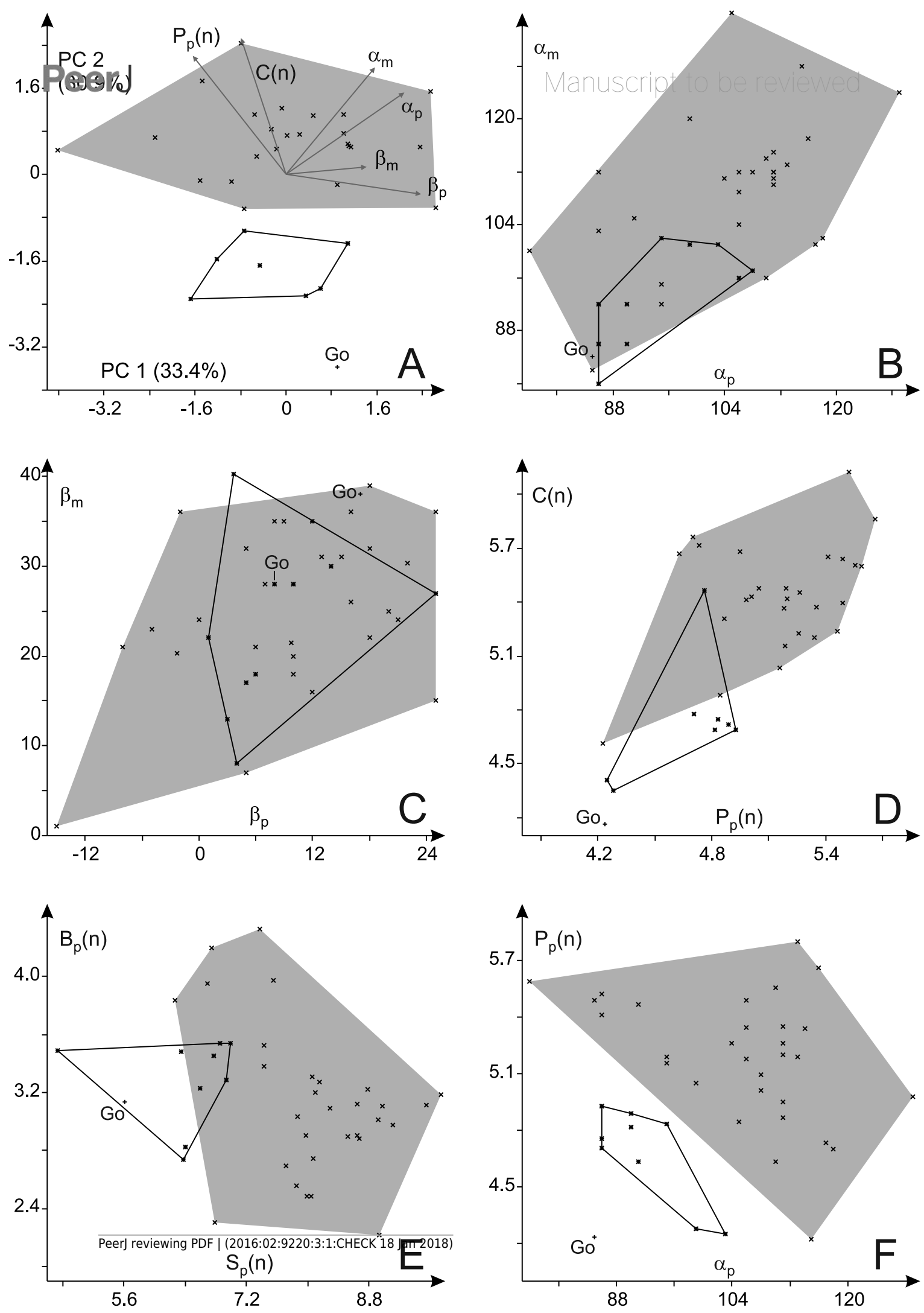
Figure 14(on next page)

Variability in toe proportions and trackway parameters of Ichniotherium cottae with relatively short pedal digit $\mathrm{V}$ from nine localities.

A-B, Toe ratio plots; C, biplot for a Principal Component Analysis (PC 1 vs. 2) based on six variables; D, manual vs. pedal imprint orientation; E, pedal pace length (normalized) vs. pedal pace angulation; F, gauge width (normalized) vs. stride length (normalized). Unfilled circles represent average toe ratios and step cycles of the Tłumaczow and Marietta specimens. 
Figure 15 (on next page)

Morphospace occupation by different samples and morphotypes of Ichniotherium with relatively short pedal digit $\mathrm{V}$.

A, Plot of linear discriminant function values against angle of pedal imprint orientation $\left(\beta_{p}\right) ; B$, Scheme illustrating trackway parameters and toe ratios that allow pair-wise distinctions between three morphotypes and the Maroon sample (two localities). Labels: Ma, Marietta/Ohio; TI, Tłumaczow/Poland. 
$F(1)=0.226^{*} \alpha_{p}\left[{ }^{\circ}\right]+7.786^{*} P_{p}(n)-60.405$
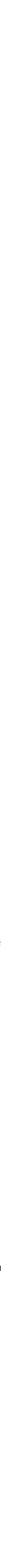
Figure 16(on next page)

Nomograms for simple discrimination of Ichniotherium cottae morphotypes in the field. 


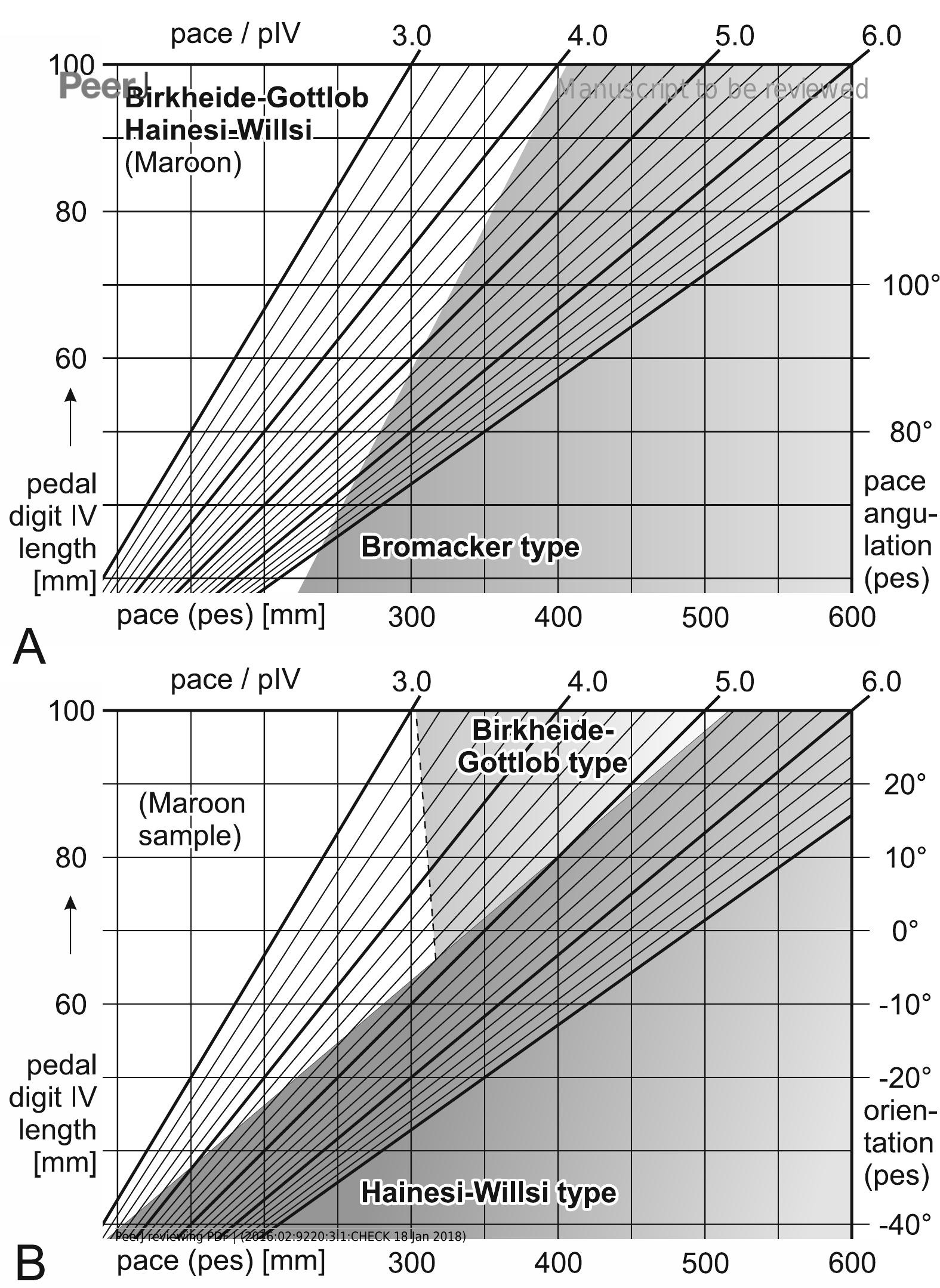


Figure 17 (on next page)

Data for the three proposed morphotypes of Ichniotherium cottae in stratigraphic order may reflect changes in trackway pattern over time.

A, Histograms depicting the distributions of six trackway parameters for each of the three types (number of counts = step cycles per bin). B, Averages of imprint and trackway parameters. The sample from Gottlob quarry (G, the type locality of I. cottae, Goldlauter Formation) lacks a sufficient number of complete step cycles, so only toe proportions of the Gottlob sample have been considered independently from those of the Birkheide record ( $B$, Oberhof Formation) in the left part of the table. 


\section{Figure 18(on next page)}

\section{Phylogenetic hypotheses for the trackmakers (TMs) of the Ichniotherium ichnospecies and morphotypes.}

A, Tree-like depiction of the evolutionary changes of Ichniotherium trackway patterns within the morphospace of body-size normalized gauge width versus stride length. Number on trackway diagrams refer to pedal/manual imprint orientation angles, pedal/manual pace angulation, normalized pedal pace length and apparent trunk length. For the Hainesi-Willsi (H-W) type of $I$. cottae only imprint orientations differ notably from that of the Gottlob-Birkheide (G-B) type and are depicted here. Average values for $I$. sphaerodactylum and I. praesidentis are based on Voigt (2007) and Voigt \& Ganzelewski (2010), respectively. Evolutionary steps no. 1-2: decrease in normalized gauge width and distance from pedal to manual imprint of an imprint pair (in the direction of movement), increase in pace angulation and in normalized stride length, orientation of the manual imprints changes from outward (supination) to midlineparallel; no. 3: transition in pedal imprint orientation from outward to midline-parallel and in manual imprint orientation from midline-parallel to inward (pronation); no. 4: increase in pace angulation, in normalized pace length and stride length; no. 5: increase in pace angulation and in normalized stride length, orientation in pedal imprints changes from outward to midline-parallel, in manual imprints change from midline-parallel to inward orientation. B, Phylogeny for all considered Ichniotherium trackmakers with nodes a-c and evolutionary steps 1-5 labeled as in A. The arrows marks supposed correlations of ichnotaxa with fossil tetrapod orthotaxa. In accordance with the phylogenetic hypotheses of Reisz (2007) and Kissel (2010) node a might represent the last common ancestor of all diadectomorphs whereas node $b$ represents the last common ancestor of Orobates, Diadectes and its allies. Node c corresponds to the DesmatodonDiasparactus-Diadectes clade (including "Silvadectes" in Kissel, 2010). Node d could represent the Diadectes lineage of Reisz (2007) and has no clear correspondence in Kissel's (2010) hypothesis. 
gauge widger rJ normalized

$B_{p}(n)$

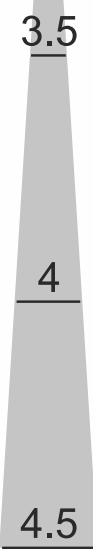

A
I. cottae
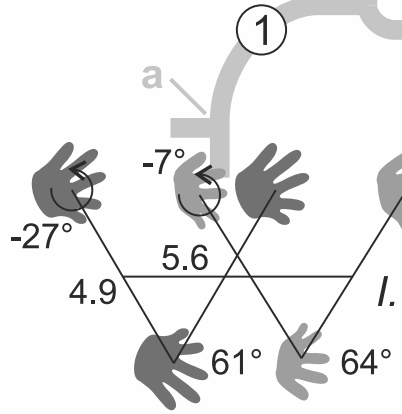

15
(3)

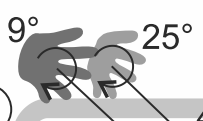

(2)

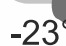

$-23^{\circ}$

(H-W)

(B-G)

(4)

5.2

$106^{\circ} / 109^{\circ}$

(Bromacker)

(5)

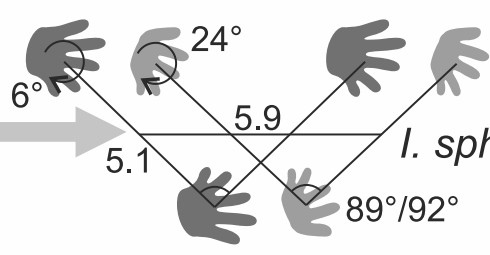

stride length normalized

$S_{p}(n)$

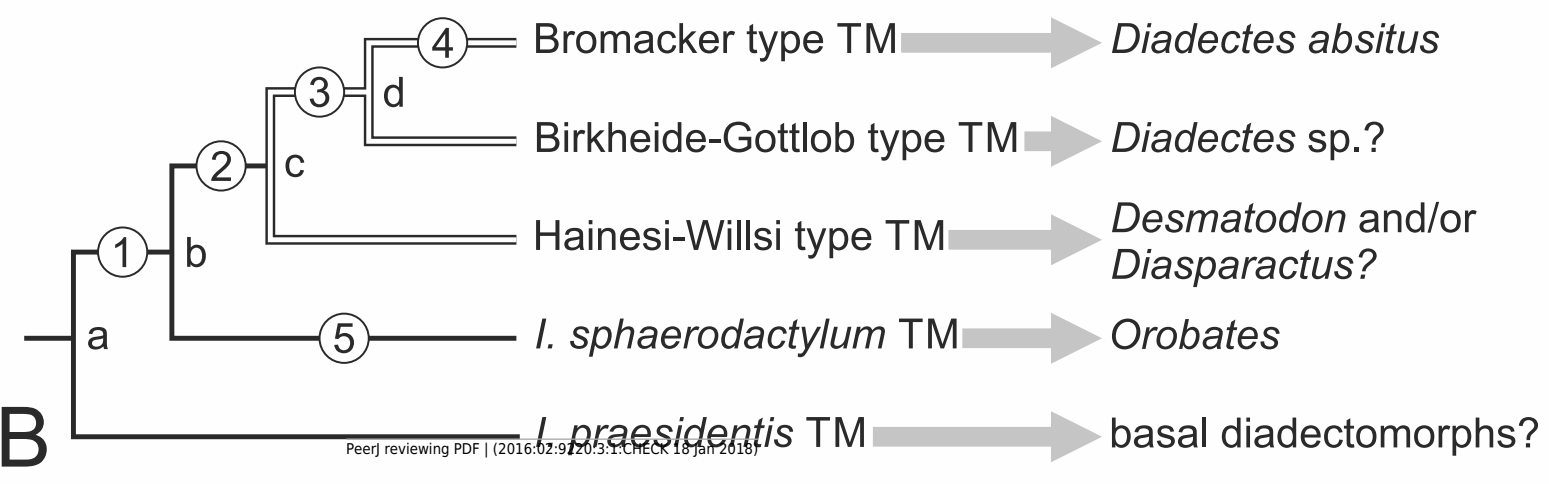

